\title{
Herpes simplex virus type 1 and Alzheimer's disease: link and potential impact on treatment
}

\section{Roberta Mancuso, Mariaconcetta Sicurella, Simone Agostini, Peggy Marconi \& Mario Clerici}

To cite this article: Roberta Mancuso, Mariaconcetta Sicurella, Simone Agostini, Peggy Marconi \& Mario Clerici (2019): Herpes simplex virus type 1 and Alzheimer's disease: link and potential impact on treatment, Expert Review of Anti-infective Therapy, DOI: 10.1080/14787210.2019.1656064

To link to this article: https://doi.org/10.1080/14787210.2019.1656064

Accepted author version posted online: 15

Aug 2019.

Submit your article to this journal ¿

Џll Article views: 3

Q View related articles $₫$

View Crossmark data ־ 
Publisher: Taylor \& Francis \& Informa UK Limited, trading as Taylor \& Francis Group

Journal: Expert Review of Anti-infective Therapy

DOI: $10.1080 / 14787210.2019 .1656064$

Article type: Review

Herpes simplex virus type 1 and Alzheimer's disease: link and potential impact on treatment

Mancuso Roberta ${ }^{1 *}$, Sicurella Mariaconcetta ${ }^{2}$, Agostini Simone $^{1}$, Marconi Peggy $^{2}$, Clerici Mario $^{1,3}$

${ }^{1}$ IRCCS Fondazione Don Carlo Gnocchi, Milan, Italy

${ }^{2}$ Department of Chemical and Pharmaceutical Sciences, University of Ferrara, Ferrara, Italy

${ }^{3}$ Department of Pathophysiology and Transplantation, University of Milan, Milan, Italy

*Corresponding author:

Roberta Mancuso

Senior Researcher, Laboratory of Molecular Medicine and Biotechnologies,

Santa Maria Nascente Scientific Institute,

IRCCS Fondazione Don Carlo Gnocchi

Via Capecelatro 66, 20148, Milano, Italy

Phone: +390240308375

Email: rmancuso@dongnocchi.it 
Abstract

Introduction: Alzheimer's disease (AD), the most common form of dementia worldwide, is a multifactorial disease with a still unknown etiology. Herpes simplex virus 1 (HSV-1) has long been suspected to be one of the factors involved in the pathogenesis of the disease.

Areas covered: We review the literature focusing on viral characteristics of HSV-1, the mechanisms this virus uses to infect neural cells, its interaction with the host immune system and genetic background and summarizes results and research that support the hypothesis of an association between AD and HSV-1. The possible usefulness of virus-directed pharmaceutical approaches as potential treatments for AD will be discussed as well.

Expert opinion: We highlight crucial aspects that must be addressed to clarify the possible role of HSV-1 in the pathogenesis of the disease, and to allow the design of new therapeutical approaches for $A D$.

Keywords: Alzheimer's disease, Human herpes simplex virus type-I, immunity, mild cognitive impairment, pharmaceutical treatments. 


\section{Article highlights}

- A possible role for the reactivation of HSV-1, a virus that commonly infects humans, in the pathogenesis of $A D$ is suggested by a string of observations.

- After the initial infection HSV-1 persists in latent state in trigeminal ganglia and, upon reactivation can reach the brain, as showed by detection of HSV-1 viral genome in brain of elderly people.

- Reactivation of HSV-1 can cause neuronal damage, directly and/or by induction of inflammation.

- Host immunity is critical to control viral reactivation and it is impaired in AD patients.

- If HSV-1 infection is a risk factor for $A D$, antiviral treatments could be useful in the prevention/treatment of this disease. 


\section{Introduction}

Alzheimer's disease (AD) is a common form of senile dementia that in 2018 affects 50 million individuals around the world, and that in the near future will become one of the biggest medical issue, at least in western countries, due to the increase of life expectancy. Thus, the World Alzheimer Report predicts that in 2050 a total of 152 millions of people will suffer from AD [1]. AD is an inflammatory neurodegenerative disease characterized by progressive decline of normal cognitive abilities and of intellectual impairment, with a consequent loss of working abilities and the incapacity to perform daily living activities [2] Importantly, an intermediate stage between AD and healthy aging is Mild Cognitive Impairment $(\mathrm{MCl})$, defined as a subjective and objective decline in cognitive performance that is greater than expected for individual's age and education level, but does not meet criteria for the diagnosis of dementia [3]. The brain of AD patients is mainly characterized by the presence of intraneuronal neurofibrillary tangles, formed by abnormal phosphorylated Tau protein, and extracellular senile plaques, formed by amyloid- $\beta$ (A $\beta$ ), a peptide produced by the proteolysis of amyloid precursor protein [4].

The etiology of $A D$ is still unknown: the disease is defined as multifactorial as several factors interacting with each other are suspected to be involved in its development. Amongst these factors important roles are played by genetic background, in particular the $\varepsilon 4$ allele of the apolipoprotein $E(A p o E)$ gene, infections and inflammation.

A role for pathogens in the development and progression of $A D$ [5] has long been suspected, and human spirochetes, fungi, Borrelia burgdorferi, Chlamydophila pneumomniae, Helicobacter pylori and human herpes simplex virus type 1 (HSV-1) have been envisioned as possible culprits. The possibility that HSV-1 could be involved in the pathogenesis of AD, in particular, was originally hypothesized by Ball in 1982, when he proposed that "reactivation [of HSV-1] travelling centripetally [through known anatomic nerve fiber connections into the limbic areas of the brain] might be the cause of the degenerative lesions typical both of Alzheimer's Disease and of the normal aged human brain" [6]. After the primary infection, HSV-1 can remain latent in the nervous system; very rarely, its reactivation can result in an acute and often lethal form of encephalitis [7]. In this case, the brain area involved are the hippocampus as well as the temporal and frontal lobes; interestingly these are the same brain area that are affected in AD. This observation offered one of the first supports to the Ball hypothesis. In 1991 Jamieson and coworkers found traces of HSV-1 genome in brains of sporadic AD patients; importantly viral genome was present in those areas - hippocampus, temporal and frontal lobes - typically affected by AD [8]. The importance of 
these results was somewhat diminished by the fact that HSV-1 genome was also detected in brains of non-demented elderly individuals suggesting that brain HSV-1 latent infection is a relatively frequent event. Interestingly, in 1997 Itzhaki and coworkers added a further piece to this scenario by showing that the combination of ApoE4 allele, a genetic risk factor for AD, and HSV-1 in brain, greatly augments the risk of developing $A D$ [9]. Some years later the same researchers proposed that recurrent reactivation of latent HSV-1 in brain results in localized neuron damage through direct and indirect toxic effects of the virus [10].

To note, the HSV-1 DNA detection in AD brain varies considerably in literature, from the absence [11] or small proportion of positivity (2\%) [12], to a higher DNA presence (35\%) [13], up to almost totally positive AD brain samples (70-100\%)[8,9]: differences in methodological sensitivity, reduced DNA yield extraction from fixed material with long duration of storage may be the reasons of these discrepancies. Another important aspect is that not only HSV-1, but also other herpesvirus species (i.e. HHV-6A) [14] as well as bacteria (i.e. Borrelia burgdorferi and Chlamydia pneumoniae) and fungi can be detected in brain tissues [15], highlighting the need to perform larger studies to confirm these data and to analyze the presence of other uninvestigated pathogens.

Based on literature databases (up to March 2019), in this review we summarize the main findings and results that support the presence of a link between AD and HSV-1, link that, acting in synergy with other, yet unidentified factors could have a role in the onset and development of this neurodegenerative disease.

\section{Herpes simplex virus}

Herpes simplex virus (HSV) type 1 and type 2 are human neurotropic, host-adapted pathogens whose lifestyle is based on a long-term dual interaction with the infected host that can establish both lytic and latent infections [16]. These viruses establish latent infections in sensory ganglia; such infections can undergo reactivations that can be either asymptomatic or symptomatic. In this case, cold sores, keratitis, blepharitis, meningitis, encephalitis, genital infections or systemic and severe conditions in immune compromised patients can be observed [17]. Dissemination is very common in human communities owing to latent infection, periodic reactivation, and asymptomatic virus shedding. HSV is a highly prevalent infection worldwide: $67 \%$ of the population under the age of 50 was shown to be infected with HSV-1 and 11\% harbors HSV-2 [18]. The HSV-1 infection is generally acquired during childhood, although during the past twenty years 
in developed countries a decreased trend of seroprevalence has been observed in adolescent and young adults [19].

\subsection{Structure of HSV-1}

The HSV-1 virion includes 4 components: the outer envelope, the tegument, the capsid and the core [20] (Figure 1). The envelope consists of a lipid bilayer and anchors approximately 11 viral glycoproteins, four of which (gB,gD, gH, and $g \mathrm{~L})$ are essential in allowing virus entry into cells [21]. The tegument is an unstructured amorphous layer that surrounds the capsid, it includes more than 20 proteins and is important in the regulation of viral replicative cycle [22]. The capsid is composed by 162 capsomeres that are organized within an icosahedral structure. The core is the central domain of the virus and contains the linear, double stranded, $152 \mathrm{kbp}$ DNA (dsDNA) genome. The HSV genome can be divided into two unique sequences, designated as unique long (UL) and unique short (US), flanked by large repeated sequences, internal (IRL and IRS) and terminal (TRL and TRS). The viral genome encodes approximately 90 unique transcriptional units, of these at least 84 encode proteins that can perform many functions in the infected cell.

\subsection{Virus attachment and entry}

To initiate infection, HSV-1 binds at least three different classes of cell-surface receptor and fuses its envelope with the plasma membrane. The entry of HSV-1 into epithelial cells is a complex process [23]. Its envelope contains 11 glycoproteins that are very important in mediating the initial steps of viral attachment and entry into the cell as well as facilitating cell-to-cell spread of the virus [21]. The virus enters by fusion with the plasma membrane or via endosomes through an orchestrated process that requires $\mathrm{gB}$, the most ubiquitous envelope glycoprotein in human herpesviruses, and three other essential envelope glycoproteins ( $\mathrm{gD}$ and $\mathrm{gH} / \mathrm{gL}$ ), activated in a cascade fashion.

Glycosaminoglycan-chains (GAGs) are expressed on the host cell; among these, heparan sulfate (HS) proteoglycans (HSPGs) are the primary attachment receptors for HSV gB and gC. The interaction of $\mathrm{gC}$ and $\mathrm{gB}$ with $\mathrm{HS}$ receptor is labile and is reinforced by the participation of $\mathrm{gD}$ in the process $[24,25]$. After the viral and the host membranes are brought into close vicinity, gD interacts with one or more cellular receptors [25] inducing a conformational change to the heterodimer $\mathrm{gH} / \mathrm{gL}$, modifying it into a form that interacts and triggers the fusogenic activity of $\mathrm{gB}$ [23]. By the interaction of $\mathrm{gH} / \mathrm{gL}$ with $\mathrm{gB}$, the prefusion glycoprotein shifts to a post fusion 
conformation that is capable of forming the fusion pore.

Fusion pore completes the fusion process; at this point the virion particles, along with the tegument, enter the cytoplasm. After penetration into the cytoplasm, some tegument proteins remain in the cytoplasm while other are transported to the nucleus or remain associated with the capsid that travels via microtubule network, to the nucleus [26]. The processes of transcription and replication of the viral genome, as well as the assembly of progeny capsids, take place within the nucleus.

\subsection{Lytic cycle}

Ones inside the nucleus, viral DNA is rapidly circularized and viral genes are expressed in a tightly regulated, interdependent temporal sequence. The lytic cycle of HSV-1 can be divided into three phases, which involve the expression of three groups of viral genes: $\alpha$ or Immediate Early (IE), $\beta$ or Early (E) and $y$ or Late (L) [20]. IE genes are first expressed, about 2-4 hours post-infection, by the combined action of the tegument viral protein (VP) 16, known also as $\alpha$-TIF ( $\alpha$-trans-inducing factor) with at least two cellular proteins, the octamer-binding protein (Oct-1) and the host cell factor 1 (HCF-1), that targets the TAATGARAT motif upstream of the IE promoters stimulating the transcription of five IE genes [27]. During this early stage the corresponding proteins are synthesized: infected-cell polypeptide (ICP)4, ICP27, ICP22, ICP0 and ICP47. ICP4, an essential viral protein, is a DNA binding protein that interacts with basal transcription factors, such as TATAbinding protein (TBP), TFIIB, TFIID and TAF250 [28]. This interaction activates most E and L genes and represses the transcription of other IE genes [28]. ICP27, in particular, is responsible for the post-transcriptional modifications that control viral mRNA splicing, represses the expression of some IE and E proteins and induces L protein expression [29]. ICP27 also contributes to the decrease of cellular genes expression and is an important regulator of host cell fate [29]. ICP22 plays an important role in replication and pathogenicity of HSV-1 since his function is crucial to allow the optimal expression of $E$ and $L$ genes, to promote the formation of functional virions composition, and to permit capsid nuclear egress [30]. ICP47 binds to the transport proteins TAP1 or TAP2, preventing the transport of viral peptides to the endoplasmic reticulum [31]. ICPO is a transactivator that promotes transcription of many viral and cellular genes during the lytic infection and is essential for latency reactivation [32]. ICPO is a RING finger protein and exhibits two distinct ubiquitin ligase activities that interact with different cellular E2 ubiquitin-conjugating enzymes and therefore targets different cellular substrates [32]. The major mechanism of action of 
ICPO, thus, may be the degradation of specific cellular proteins via the ubiquitin-proteasome pathway [32]. After IE gene transcription and expression, the E phase starts, this leads to the production of proteins responsible for viral DNA synthesis and packaging. Expression of E genes requires at least the presence of functional ICP4 and reaches a peak at 4-8 hours post-infection. During this phase, proteins mostly act as enzymes and are responsible for the replication of the viral genomes that are produced. Among them important roles are played by DNA polymerase (UL30/UL42 complex), thymidine kinase (TK), single-stranded DNA (sSDNA) binding protein (SSB), also known as ICP8, a DNA helicase-primase, and UL9 [20,21]. Finally, viral DNA replication stimulates the transcription of $L$ genes that mainly consist of structural proteins of the virion, such as tegument and envelope proteins, and proteins responsible for the assembly of the viral particle. The assembly of the viral particle starts in the nucleus: a procapsid, a spherical fragile intermediate is formed, the DNA is then packaged and undergoes a morphological change to become a mature icosahedral capsid $[20,21]$.

\subsection{HSV-1 infection in neuronal cells and latency establishment}

The initial site of entry within neurons is usually at the axon terminus near peripheral epithelial cells [33]. The entry mechanism in sensory nerves depends on the cell type and on the interaction of viral glycoproteins with the cellular receptors [33]. During infection of neurons, HSV-1 causes a biphasic remodeling of the actin cytoskeleton by first inactivating and then reactivating cofilin-1, resulting in F-actin assembly and disassembly during early and late stages of infection [33]. After the fusion, the capsid is transported retrogradely to the nucleus along the microtubules; this transport involves the dynein/dinactin complex [34]. Release of the viral genome in the neuronal nucleus results in its rapid association with histones to create a circular episomal DNA. Viral genes are not expressed at this stage with the exception of LAT gene which is expressed in high abundance [35]. The functions of LATs transcripts are not completely clear, but they have a fundamental role in maintaining viral latency which can silence lytic gene expression and block apoptosis [36]. During latency, chromatin plays an important role: in fact, the histones associated with the latent viral genome are often modified [35]. Experimental animal model have been used to show that in the trigeminal ganglia of infected mice the expression of genes $I E, E$ and $L$ occurs in the first 24-72 hours after infection, whereas in the following period their expression decreases and LAT transcripts accumulate: this results in the establishment of latent infection [37]. Generally sensory neurons do not express lytic proteins, but several stress stimuli may induce the 
reactivation of the virus in these neurons. The assembled capside exits the nucleus through the inner nuclear membrane and merges with the outer nuclear membrane. Viral capsids containing inner tegument proteins with or without an envelope, and vesicles associated with glycoproteins and tegument proteins are targeted for active transport along microtubules in axons using the neuronal secretory pathway. The virus is then transported in anterograde manner to the area of primary infection where a new productive infection starts [38].

\section{Virus-host interaction}

\subsection{HSV-1 and apoptosis}

Apoptosis, also called programmed cell death, is an important innate mechanism that eliminates

pathogen-infected cells. This mechanism has a crucial role in limiting viral replication and transmission emphasizing the importance of this host-interaction process in viral pathogenesis. HSV has evolved in the manner to modulate apoptosis in different cell types either with antiapoptotic genes to promote the generation of new viral progenies or with pro-apoptotic genes to promote cell death to favor viral release and shedding. LAT, US3 and many other HSV-1 genes, including ICP4, ICP34.5, UL54, US1, US5 and US6 [39] are suspected to regulate apoptosis. The ability of LAT to interfere with apoptosis correlates with its ability to promote spontaneous reactivation [40]. LAT inhibits multiple steps in apoptotic cascades and inhibit dephosphorylation of PAKT levels to promote cell survival and indirectly to control caspase 3 and block apoptosis [41]. The two small RNAs encoded by the initial part of LAT gene are involved in the inhibition of caspase 8- and caspase 9-induced apoptosis [42]. The US3 is a multifunctional protein kinase that plays various roles in the viral life cycle by phosphorylating a number of viral substrates [43]. US3, can block apoptosis, as it activates antiapoptotic substrates targeted by the cellular cyclic adenosine monophosphate (CAMP)-dependent protein kinase [44]. Benetti and Roizman have demonstrated that Us3 blocks the proteolytic cleavage of caspase 3 inhibiting its activation and consequently the apoptotic event [45]. Many other viral proteins have a role in blocking apoptosis (summarized in table 1), in particular, US5 that encodes for the non-essential glycoprotein J (gJ) inhibits caspase $3 / 8$ activation through Fas-mediated or granzyme B induced apoptosis $[46,47]$.

\subsection{HSV-1 and host immunity}

Multiple innate immune pathways cooperate to form a barrier to viral infection: particular receptors (called pattern recognition receptors, PRRs) survey cells surface and intracellular compartments for specific pathogen-associated patterns (PAMPs), including viral DNA, RNA and 
proteins. Toll like receptor-2 (TLR2) recognizes HSV-1 envelope glycoproteins ( $g D, g H, g L$ and gB), whereas on TLR9 and TLR3 detect respectively viral GC-rich/AT-repeated DNA regions and double strand RNA (dsRNA) [48]. TLR3, in particular, has an important protective role against HSV-1, as witnessed by the observation that patients with TLR3 dominant negative mutations are more susceptible to herpes simplex encephalitis [49].

A number of cytosolic receptors have been suggested to sense HSV-1 nucleic acid as well. Thus, RIG-1 and MDA-5 sense dsRNA whereas other receptors (cGAS, DNA-PK, DAI, IFI16, DDx41, DHx9, DHx36) are activated by viral DNA, although for many of these receptors the precise mechanism remains to be investigated [48].

After the binding of viral ligands to receptors, adaptors (such as MyD88, TRIF, MAVs, STING) are recruited, kinase proteins (as IKK, TBK) are activated and, after nuclear translocation of transcription factors (NF-Kb; IRF3; IRF7), type I IFNs (IFN- $\alpha$ and IFN- $\beta$ ) are generated; IFNs are crucial for the control of infection as they production induces the expression of hundreds of responsive genes (ISGs), among which pro-inflammatory cytokines (IL-6, IL-12, TNF $\alpha$ ) and chemokines (CXCL-10, CXCL-9) that promotes viral clearance through the recruitment of specialized immune cells.

The inflammasome is activated as well by HSV-1: this process is started by DNA binding to sensor molecules (IFI16 and NOD-like receptor family pyrin domain containing 3 or NLRP3) and results in the production of the pro-inflammatory cytokines IL-1 $\beta$ and IL-18 [50]. IFI16 (IFN $\gamma$-inducible protein 16), in particular, is another important player in the immune response to HSV-1. Thus, IFI16 binds the viral genome in the cytoplasm of the infected cell through STING/IRF3 proteins [51]; this leads to type 1IFNs expression, and, through the activation of the inflammasome to IL$1 \beta$ and IL-18 release. Notably this proteins has a nuclear action as well, as in the nucleus it promotes heterocromatin assembly on HSV-1 DNA and silences HSV-1 expression [52]. Another central element of innate immunity is the complement system, whose components (in particular C1q e C3b) can directly bind to HSV-1. This leads to antibody (Ab)-mediated neutralization of the virus, inhibition of receptor binding on the surface of cells, reduction of the infectivity, and lysis of infected cells. The classical pathway of the complement is also triggered in an antibody-independent manner when $\mathrm{C} 1$ directly binds to virions or to infected cells. The complement system is also essential in the regulation of adaptive responses by enhancing $\mathrm{T}$ and $\mathrm{B}$ lymphocytes-mediated responses. 
The production of cytokines and chemokines induces adaptive antigen-specific cell response. Viral antigens, bound to MHC-I and presented by antigen presenting cells (APC), are recognized by CD8+T lymphocytes, this results in the activation of their effector mechanisms and the establishment and maintenance of memory T cells. Granzymes and perforins induce the lysis of infected cells; IFN- $\gamma$ production by activated T lymphocytes enhances the processing of viral peptides that will be presented by MHC, thus expanding the potency of cells-mediated immune responses.

Overall, if the innate immunity system mainly controls the initial phase of HSV-1 replication, cellmediated adaptive immunity play a major role in preventing reactivation from latency and limiting of viral spread [53].

A novel population of T cells known as tissue-resident memory CD8+ (TRM) T cells has been recently described, these cells are critical for peripheral immune surveillance and protection against viral infection [54]. Following a primary HSV-1 infection, CD8+TRM cells are generated and retained for long time in non-lymphoid tissue, including ganglia and mucosa [55]. CD8+TRM survey latently infected niches, if infected cells are detected, IFN- $\gamma$ and granzyme B will promptly be produced. The regulation mechanisms for TRM cell during viral reactivation in central nervous system (CNS) remain unclear but it is conceivable that vaccines boosting the resident CD8+TRM cells could be a viable option for protection against HSV-1 infection and/or reactivation. $\mathrm{CD}^{+}{ }^{+} \mathrm{T}$ cells are critically important for the prevention of HSV genital infection [53] and they are responsible for herpes stromal keratitis, following the production of Th1 cytokines. Notably, these cells are also present in sensory ganglia and spinal cord, where they mediate clearance of HSV-1 from neural tissue and persist for a long time after infection.

The Ab response to HSV-1 infection is broad, polyclonal and is mainly directed towards envelope glycoproteins as well as toward tegument and capsid proteins [56]. During infection gD and gB are the most important viral proteins in stimulating the production of IgGs; these Ab will then prevent the interaction between HSV-1 and its cell receptors, neutralizing viral infectivity. The role of humoral immunity in protection against HSV-1 infection is however still controversial [57]: naturally induced $\mathrm{Abs}$ are not able to protect from viral reactivation and to completely avoid virus transmission. This is at least partially the consequence of the ability of the virus to develop immune evasion strategies to inhibit neutralizing $A b$ response, including transmission through the cell-to-cell spread that protects the virus from immune surveillance. 
Interestingly, HSV-1-specific cell-mediated immune responses can be detected in HSV-1 seronegative individuals [58]; this could be a consequence of HSV-1 cross-reactivity with other herpesviruses, including varicella zoster virus (VZV): these two viruses in fact present homologies in numerous genes; immunity related to VZV infection or vaccination could thus modulate HSV-1 or HSV-2 infection and vice versa [59].

Notably attempts to obtain an effective vaccines based on induction of $A b$ response by $g B / g D$ envelope glycoproteins, showed only limited efficacy in humans, suggesting that a more complete protection against HSV-1 infection might be obtained upon stimulation of high titers of neutralizing Abs and, likely, by designing vaccines that will preferentially stimulate HSV-1-specific cell -mediated immunity (in particular tissue resident memory T-cells [60].

\subsection{Evasion from host immunity}

HSV-1 has evolved several mechanisms to counteract the host immune response, allowing its persistence in infected hosts humans (reviewed in 48 and 61 and summarized in Table 2). Usually the host uses the xenophagy - i.e. the autophagic degradation of intracellular pathogens - to block HSV-1 infection [62]. HSV-1 xenophagy is stimulated by type 1 IFNs and is mediated by antiviral proteins, including the double stranded RNA-dependent protein kinase R (PKR). PKR is activated upon binding a double-stranded RNA; this precludes protein synthesis in virus-infected cells by phosphorylation of the $\alpha$ subunit of eukaryotic initiation factor 2 (elF-2 $\alpha$ ). HSV-1 produces two different proteins to evade this defense mechanism: US11 and ICP34.5. In particular, US11 directly binds to PKR, blocking its phosphorylation and inhibiting its activity, whereas ICP34.5 recruits phosphatase proteins of the host to phosphorylate elF $2 \alpha$ with consequent translation blockage. Both these two viral proteins are required for full resistance to type 1 IFN-mediated immune response, as both inhibit autophagic degradation of HSV-1 proteins [63]. To note, ICP34.5 is able to inhibit autophagy also in an alternative way, binding the essential autophagy protein beclin 1. LAT also can interfere with the type 1 IFN pathway, as it was demonstrated in animal models that this transcript regulates the expression of IFN in neurons [64]. Another HSV-1 key protein is the US3 tegument protein. US3 dampens the IFN- $\beta$ signaling and reduces IFN $-\gamma$ production by cytotoxic T lymphocytes, protecting the infected cells from lysis [65]. US3 can also modulate TLR responses, inhibiting the TLR2 and TLR3 signaling, and, in association with gB, interfering with the activity of natural killer cells, by inhibiting CD1d antigen presentation and their consequent activation [66]. 
Finally, HSV-1 can also evade the complement-dependent host immune response by binding the viral Fc receptor ( $\mathrm{VFcR}$ ) to the Fc end of IgGs; this results in the suppression of complementdependent neutralization and the survival of infected cells.

\subsection{Control of HSV-1 reactivation}

Normally the nervous system activates effective innate and adaptive immune responses to contain HSV-1 infection [67]. In particular, upon HSV-1 infection human microglia cells produce a number of pro-inflammatory cytokines and chemokines [68], with a concomitant activation of lymphocytes to control viral replication [69]. Therefore, a delicate balance between host surveillance and viral immune evasion mechanisms drives HSV-1 into latency. The virological mechanisms, related to latency and reactivation, have been extensively investigated $[16,69]$. The absence of viral product during latency in neurons lead to hypothesize that cellular factors act as "trigger" for HSV-1 reactivation, but we have only a partial knowledge of these factors. Reactivation can be induced in humans by environmental stress (UV radiation, fever, fatigue, hormonal change, cranial trauma, immunesuppression) and by other stimuli (i.e. NGF deprvation or histone deacetilase inhibition), as observed in cultured neurons or using animal models [16]. It is important to underline that these experimental approaches are often imperfect and they don't completely represent the natural occurring reactivation in humans, where probably other characteristics (related to cell type, species, or viral strain) can determine the results of this complex mechanism. Other concomitant infections, as i.e. with human Cytomegalovirus (CMV) [70], can be considered as well

important factors inducing HSV-1 reactivation. The current understanding of the factors regulating latency reactivation is limited yet and much more knowledge should be gained before to have a clearer picture of viral reactivation process.

In vivo studies in the murine model showed that HSV-1-infection of trigeminal ganglia results in the expression of major histocompatibility complex (MHC) class II antigens and triggers the production of pro-inflammatory and neuroinflammatory cytokines and proteins [71]. Interestingly, in the case of encephalitis, disease severity and the disruption of the blood-brain barrier are the consequence of the pro-inflammatory response to the virus [72], and immune markers of lymphocyte activation remain increased in cerebrospinal fluid for many months after the resolution of infection [73].

It is believed that reactivation can be controlled mainly by an efficient generation of $\operatorname{CD} 8^{+}$and to a lesser extent of $\mathrm{CD} 4+\mathrm{T}$ lymphocytes. Most of the $\mathrm{CD} 8+\mathrm{T}$ cells infiltrating trigeminal ganglia (TG) are 
activated and secrete IFN- $\gamma$ or TNF- $\alpha$, but only few also express granzyme B. IFN- $\gamma$ inhibits the expression of ICPO, a potent transactivator of viral genes that promote lytic cycle and granzyme B can degrade the IE protein ICP4, inhibiting viral replication in the absence of neuronal apoptosis [74].

Induced regulatory T cells (iTreg) were recently indicated to be an HSV-1 "latency switch" through the regulation of HSV-1 specific $-\mathrm{CD}^{+}{ }^{+} \mathrm{T}$ cell. Thus, after acute primary infection, iTregs increase, this facilitates HSV-1 latency by suppressing cytotoxic response. Environmental stresses, on the other hand, result in an increase of iTreg cells and modulate glucocorticoid expression; this results in a decrease of $\mathrm{CD}^{+} \mathrm{T}$ cell surveillance and HSV-1 reactivation [75]. Although further study are needed to better understand the fine mechanism of their interaction with $\mathrm{CD} 8^{+} \mathrm{T}$ cells, manipulation of iTreg-cell-based could help in the prevention of damages derived from HSV-1 reactivation.

Most of HSV-1 infected individuals are "asymptomatic", as viral reactivation is infrequent. In addition, only a minority of "symptomatic" subjects shows evident symptoms and recurrence of disease. The complex mechanisms that lead asymptomatic subjects to be "naturally protected" from clinical disease, are not completely known, and seem to derive from variations in the number and nature of the HSV-1 antigens (mainly gB and gD) that are targeted by cell immunity [76]. The identification of these "protective" epitopes, that characterize naturally protected individuals, represents a remarkable advance in the understanding of the immunological control of HSV-1 reactivation. Studies on whole profiles of "protective" or "pathogenic" HSV-1 antigens will help to develop new effective vaccine strategies. Moreover, the phenotypical and functional characterization of the viral epitopes that are presented to T lymphocytes in relation to different HSV-1 clinical manifestation will further clarify the nature of the relationship between host immunity and pathogenesis.

\section{The interplay between HSV-1 and AD}

\subsection{HSV-1 specific immunity in AD patients}

Evidences of microglia-mediated inflammation in AD brain have been reported by many authors. Thus, in AD brains, TLR expression is upregulated and pro-inflammatory cytokines and chemokines are produced $[77,78]$. Although it is hard to know if these features are a consequence of the disease or contribute to its pathogenesis, a realistic hypothesis is that a vicious cycle is created, where IFN- $\gamma$-producing T cells infiltrate the CNS [79], driving A $\beta$ deposition/accumulation, while $A \beta$ 
activates glial cells to produce others inflammatory mediators, leading to chronic process of neuronal dysfunction and cellular death.

In a recent work, De Chiara and co-authors have established a mouse model of HSV-1 infection where they show AD-like phenotype in animal brains after multiple viral reactivation after thermal stress. In this work they demonstrated that the accumulation of $A \beta$, hyperphosphorilated Tau and cognitive deficit was proportional to the numbers of HSV reactivations [80]. HSV-1 repeated reactivations from latency are likely to have a significant impact on the pathogenesis of $A D[6]$ as such reactivations would concur to neuronal damage directly, via viral action and indirectly as a consequence of the upregulation of neuroinflammation. Several authors investigated the possible role of HSV-1 in the pathogenesis of AD by analyzing HSV-1-specific humoral immunity [reviewed in 81]. After a first important prospective study correlating the presence of HSV-1 specific IgM (an indicator of episodes of HSV-1 reactivation) with risk to develop AD [82], other authors observed that elevated HSV-1-IgG Ab titers are significantly more frequent in patients compared to agematched healthy controls [83]. A positive correlation between HSV-1-specific IgG titers and the cortical volumes of brain regions typically affected in $A D$ was also described in mild $A D$ patients [84]; this data indicate a possible protective role of HSV-1-specific humoral immunity in the early phase of AD. Notably, this effect is specific for HSV-1, as no relations were observed between CMV- and human herpesvirus 6 (HHV-6)-specific Abs and either magnetic resonance imaging (MRI) or clinical parameters in AD patients $[84,85]$.

At least two other experimental observations favor the hypothesis that HSV-1-specific Abs have a protective effect against AD development. Thus: 1) AD incidence increases with age, possibly as a consequence the natural decline of the potency of immune responses seen in senility [86]; 2) agedependent $\mathrm{BBB}$ injuries, although detected in normal brain, are more pronounced in $\mathrm{MCl}$ subjects compared to age-matched normal subjects [87]: consequently the high concentration of HSV-1 specific Ab could limit viral reactivation in that brain regions where the BBB is disrupted. The efficacy of humoral responses is also modulated by Ab avidity, that is the relative strength with which Abs bind antigens. A significantly increase of the HSV-1 IgG avidity index was described in $\mathrm{MCl}$ compared to AD individuals [88]; additionally another study showed that HSV-1-specific Ab avidity was significantly higher at baseline in $\mathrm{MCl}$-non-converters compared to those $\mathrm{MCl}$ who did develop AD [89]. Notably, in that study, a positive correlation was observed between avidity of Abs and cortical volumes (MRI analyses). However, other experiments are needed to better understand the role of $A b$ avidity in neurodegeneration. 
The biological properties of Abs are different in different IgG subclasses. A comparative analysis of the distribution of the four HSV-1-specific IgG subclasses showed a significantly increased frequency of HSV-1-specific IgG3, the subclass with the strongest complement activation ability, in $\mathrm{MCl}$ compared to AD and healthy controls $(\mathrm{HC})[90,91]$. It is also known that at least three HSV-1 envelope glycoproteins regulate complement system and are able to prevent or reduce phagocytosis-mediated virus neutralization: the heterodimer gE-gl binds Fc portion of Ab molecule and function as IgG Fc receptor (vFcyR) [92]. Moreover gC directly binds complement components (C3 and C5), inhibiting complement activation and virus neutralization as well as complement mediated lysis of infected cells [93]. It is important to note that HSV-1 specific IgG3 Abs also have the highest neutralizing capacity of all Ab subclasses [94]. The development of an IgG3 response in $\mathrm{MCl}$ patients could thus be interpreted as an attempt to prevent HSV-1 reactivation. Finally, the protective effect of Abs in the early phase of $A D$ could be also due to $C D 4^{+} T$ lymphocytes functional impairments: a recent paper showed that Ab access to neuronal tissues is controlled by local secretion of IFN $-\gamma$ from $\mathrm{CD}^{+}$memory T cells in a mouse model of genital HSV infection [95]. To note, other viruses are suggested to be involved in cognitive impairment, as Epstein Barr virus (EBV) and CMV [96]: new researches are surely needed to better understand if one or several microbes are involved in AD.

\subsection{HSV-1, amyloid beta and calcium}

One of the major hallmark of $A D$ is the presence of cortical senile plaques in the brain of affected patients [4]. The major component of these plaques is $A \beta$, that derives from the cleavage of the ubiquitous membrane protein amyloid precursor protein (APP) that in central nervous system (CNS) is expressed by neurons, astrocytes and microglia in 8 different isoforms. Its primary physiological function is not known, but it seems to be involved in neuronal survival, synaptic plasticity and cell adhesion [97]. In healthy individuals APP cleavage is mainly mediated by $\beta$ secretase, while in $A D$ patients $\gamma$ pathway is more enhanced resulting in overproduction of $A \beta$, in particular its fragments 1-40 and 1-42, which are derived from the cleavage of precursor protein (APP) by $\beta$ - (BACE-1) and $\psi$-secretases. $A$ direct relation between $A \beta$ and HSV-1 was demonstrated in an vitro study showing that HSV-1 infection of human neuroblastoma cells reduces APP levels and increases the APP 55 KDa C-terminal fragment. Moreover, HSV-1-infected human neuronal and glia cells were shown to be characterized by an increase of BACE- 1 and $\gamma$-secretases, leading a concomitant intracellular increase of $A \beta 1-40$ and 1-42 [98]. The brain accumulation of $A \beta$ 1-42 
was then confirmed by studies performed in HSV-1 infected BALB/C mice [98] as well as in HSV-1 infected human and rat neuronal cells [99]. Data in rat cortical cells indicated that HSV-1 plays a role in the dualism between $\mathrm{Ca} 2+$ and $A \beta$, since the $\mathrm{Ca} 2+$ signalling attendant to viral attachment and entry induce modifications in APP that lead to its cleavage and the consequent formation of $A \beta$ 1-42 accumulation [100]. These findings are particularly interesting as AD mice are characterized by elevated levels of $\mathrm{Ca}^{2+}$ in neurons [101], and genes involved in calcium signaling are deregulated in neurons of AD brains [102]. Furthermore, the link among HSV infection and AD amyloid plaques formation are associated also to the homology between the internal amino acid sequence of HSV-1 glycoprotein $B(g B)$ and the carboxyl-terminal region of $A \beta$; therefore the intracellular processing of $\mathrm{gB}$ in neurons can lead to the generation of amyloid fragments that accelerates in vitro $A \beta$ aggregation [103]. Moreover it was found that the Us11 HSV-1 protein ligates a microtubule-binding protein involved in APP trafficking [104], possibly altering its cellular distribution [105].

The co-localization of HSV-1 DNA and amyloid plaques in AD patients' brain, besides being a strong evidence of a possible relation between HSV-1 and AD, supports the idea that $A \beta$ could have an antimicrobial role and could be secreted to protect neurons from injuries [106]. In the case of HSV1 , in particular, in vitro and animal studies demonstrated that repeated viral reactivations can result in APP processing and accumulation of $A \beta$ and other APP fragments, although a direct effect of HSV-1 on $A \beta$ accumulation remains to be confirmed in humans in vivo. $A \beta$ anti-infective activity has been recently showed, even if its accumulation as oligomer results neurotoxic and can cause the destruction of brain structure and functionality [107].

\subsection{HSV-1 and tau protein}

Another hallmark of $A D$ pathology is the hyperphosphorylation of tau protein. The main function of this protein is to stabilize microtubules, a process regulated by its phosphorylation. The normal level of tau phosphorylation is a consequence of dynamic regulation of tau kinases and tau phosphatases.

In $A D$, the hyperphosphorylated tau is aggregating in paired helical filaments (PHF) and neurofibrillary tangles (NFT) and can no longer perform this role. It has been proposed that this fact induces microtubules disintegrations dismantling cytoskeleton and thus neuronal transport [108]. This may first affect communications between neurons and finally lead to cell death [109]. Thus, HSV-1 infection causes an increase of hyperphosphorylated tau protein in murine cells [110], 
and in neuroblastoma cells [111]. Wozniak and co-workers have demonstrated that HSV-1 phosphorylates several sites of tau by inducing over-expression of two enzymes: GSK3 $\beta$ and PKA which are involved in protein phosphorylation [112]. To note, treatment of neuronal cells with antiviral drugs prior to HSV-1 infection prevents tau protein hyperphosphorylation [110].

\subsection{HSV-1 and autophagy}

Autophagy is the physiological mechanism used by cells to disassemble and degrade unnecessary or dysfunctional components. $A D$ is associated with a deregulation of such mechanism; this results in a decreased clearance of $A \beta$-containing autophagic vacuoles, and $A \beta$ accumulation [113]. An in vitro study on human neuron cells demonstrated that HSV-1 directly impairs autophagy, increasing the intracellular accumulation of autophagosomes [114] and reducing $A \beta$ autophagic degradation [115].

\subsection{HSV-1 and oxidative stress}

The reciprocal balance between free radicals and antioxidants is altered as well in $A D$, where oxidative stress with a consequent damage to cellular molecules is present. Thus, DNA, RNA and proteins that are damaged as a result of oxidative stress are observed in the AD brain [116]; of note, oxidative stress is one of the main culprits for neuroinflammation and neurodegeneration. In vivo studies have proven that HSV-1 can cause oxidative stress and neuronal damage in rabbits [117] as well as in mice [118]; these findings were confirmed in human neuronal cells, where oxidative stress was shown to also result in intracellular accumulation of $A \beta$ [119]. Notably, HSV-1 can induce oxidative stress via mitochondrial damage, another cellular alteration seen in AD [120], can interfere with axonal transport of mitochondria in rat neurons in vitro [121] and can induce the degradation of mitochondrial DNA and mRNA in cell lines [122].

\subsection{HSV-1 and host genetics}

The major AD-associated genetic risk factor is ApoE [123]. ApoE codes for ApoE protein, a fatbinding 299 amino acid glycoprotein component of lipoproteins that plays a fundamental role in the maintenance and homeostasis of neurons. Three different isoforms of ApoE exist, and each of them differs in the ability to accomplish these critical tasks. In brain tissues, ApoE is produced by astrocytes and microglial cells, and is involved in different pathways, including lipid transport, lipid metabolism regulation, synaptic plasticity, cell signaling and neuroinflammation. Interestingly, 
ApoE2 and ApoE3 isoforms are very effective in maintaining and repairing neuronal cells, whereas ApoE4 works less efficiently. Several studies showed that ApoE4 is the major known genetic risk factor for $A D$ [reviewed in 123]. Although the exact mode of ApoE4 action in AD is unknown, higher HSV-1 viral titers and an increased expression of HSV-1 IE genes were detected in brains of cognitive deficits-affected mice carrying ApoE4 genotype [124].

A working hypothesis tying together AD, ApoE4 and HSV-1 is that ApoE4 competes with HSV-1 for attachment to the viral entry receptors HPSGs less effectively than ApoE3 and ApoE2 [125]. Other susceptibility genes for AD were identified in genome-wide association studies (GWAS); these include phosphatidylinositol binding clathrin assembly protein (PICALM) and nectin 2 (NC-2). Both these genes produce proteins that are associated with HSV-1 lifecycle: in particular PICALM is involved in the viral exit from the nucleus [126], whereas NC-2 codes for the HVEb adhesion molecule, one of the receptors for the entrance of HSV-1 into host cells [127].

Another group of susceptibility genes for $A D$ are genes involved in the host immune response against infection. In particular: 1) clusterin inhibits the formation of the membrane attack complex (MAC), usually activated by infection, by interacting with several of its components [128]; 2) complement receptor 1 (CR1) binds complement C3 components, blocking the complement pathway and preventing the formation of MAC [129]. Interestingly, the HSV-1 glycoprotein C is a CR1 mimics and it binds the complement C3 components, turning off the complement pathway. Another gene involved in AD development is cholesterol 25-hydroxylase $(\mathrm{CH} 25 \mathrm{H})$. This protein regulates lipid metabolism, and is increased in the temporal cortex and the hippocampus of $A D$ patients; notably high levels of $A \beta$ deposits were observed to be associated with specific single nucleotide polymorphisms (SNPs) of the $\mathrm{CH} 25 \mathrm{C}$ gene [130]. $\mathrm{CH} 25 \mathrm{H}$ is an interferon-stimulated gene involved in the host immune response against viruses, HSV-1 included. In fact, $\mathrm{CH} 25 \mathrm{H}$ interacts with 25 -hydroxycholesterol $(25 \mathrm{OHC})$, a protein that prevents HSV-1 infection by blocking the virus-cell fusion [131]. Moreover it was demonstrated that chronic upregulation of $25 \mathrm{OHC}$ due to infections causes the accumulation of non-soluble cholesteryl esters in the brain, leading the cerebral vessel atherosclerosis with vascular occlusion, which contributes to AD pathology [132]. Other results showed an association between IFN- $\Lambda$ pathway genes SNPs and AD. IFN- $\Lambda$, includes four structurally related IFN- $\Lambda$ molecules $(\Lambda 1, \wedge 2, \wedge 3$ and $\wedge 4)$ endowed with potent antiviral activities. Interestingly, specific SNPS on IFNL3 and on IRF7, a fundamental transcriptional regulator of IFN-dependent immune responses, are associated with HSV-1 antibody titers in AD and $\mathrm{MCl}$ patients [133]. A very recent study showed that G78R, a particular variant of the paired 
Immunoglobulin-like type 2 receptor alpha (PILRA) a negative regulator of inflammation in myeloid cells, is protective against AD [134]. HSV-1 uses PILRA as an entry receptor [135], and G78R down regulates the ability of PILRA to bind endogenous and exogenous ligands, HSV-1 included. Finally, because several IL-10 SNPs were suggested to be a risk factor for AD [136], and because IL-10 plays an important role in HSV-1 reactivation [137], it cannot be excluded that SNPs interfering with IL10 production, modulate HSV-1 reactivation.

\section{Pharmaceutical treatment: HSV-1 and Alzheimer's Disease}

If HSV-1 is a risk factor for AD, the use of antivirals should be considered in this disease, especially when one considers that current $A D$ therapies are only marginally efficacious [138]. Thus, cholinesterase inhibitors and memantine are the only FDA-approved medications for AD but their effect is extremely limited as they do not alter the course of the disease $[138,139]$. In vitro studies in which anti-HSV-1 antiviral agents, including acyclovir, penciclovir, and foscarnet were analyzed showed that these drugs reduce HSV-1 particles as well as A $\beta$ and P-tau accumulation [140]. Notably, a recent retrospective study performed in a large Taiwanese cohort [141] suggested that HSV infection is associated with an increased risk of dementia and that this risk decreased after treatment with anti-herpetic drugs. Two other articles studied the possible relation between dementia and reactivation in older age of another herpetic virus, the varicella zoster virus (VZV), reporting an increased risk of cognitive decline after herpes zoster ophthalmicus (HZO) [142] and a decrease in incidence of dementia in $\mathrm{HZO}$ subjects treated with anti-herpetic antiviral [143]. The use of antivirals, notably, could down modulate CNS inflammation, reducing the production of pro-inflammatory molecules, $A \beta$ and hyperphosphorylated tau proteins. Early combination of neuroprotective and anti-inflammatory agents may represent an efficacious approach to AD. Natural products, and more specifically polyphenols, have been reported as promising antiviral and agents for treatment of neurodegenerative disease [144]. Phytochemicals including flavonoids, alkaloids, terpenoids and phenols are of considerable interest for the treatment of such diseases [144]. Flavonoids are naturally occurring, biologically active, and therapeutically effective polyphenols endowed with antiviral, anti-allergic, anti-inflammatory, antitumoral, and antioxidant activities [145]. They can cross the BBB and may exhibit neuropharmacological activities, influencing the protein function and gene expression. Genistein is phytoestrogen in soybean and proficiently mimics the pharmacological functions of estrogen. It can act as estrogen receptors (ERs) agonist, and could reduce A $\beta$-induced toxicity [146]. Daidzein, another flavonoid, binds ERs 
in the brain and, because of its structural similarity with estrogen, it acts as a neuroprotective agent antagonizing the action of estrogens [146]. Luteolin has anti-inflammatory and antioxidative properties, and its protective effect on the hippocampus structure and learning flaws has been studied in a AD rat model [147]. Apigenin and acacetin could inhibit the activation of proinflammatory cytokines and nitric oxide (NO) production, protecting AD neurons from inflammatory-induced stress [148]. Epigallocatechin gallate (EGCG) acts as a potent anti-oxidant agent and prevents the hippocampal neuronal cell death [149]. Cyanidin-3-glucoside (C3G) is a naturally occurring anthocyanin. Results obtained in SK-N-SH neuroblastoma cell line showed that C3G reduces $A \beta$ 1-42 accumulation, $\mathrm{H}_{2} \mathrm{O}_{2}$-induced neurotoxicity, ROS production and dampens the $A \beta$-induced expression of ER stress proteins [150]. Pelargonidin (PEL), an anthocyanin, crosses the BBB, inhibits inducible nitric oxide synthase (iNOS), a pivotal driver of oxidative stress, as well as NO production and NF-KB expression [151]. All these products can modulate molecular pathways that are altered by HSV infection.

Other natural products with an antiviral action and the ability of inducing protection from neurodegeneration are Resveratrol (RSV) and Quercetin, which are known activators of Sirt1 (NAD ${ }^{+}$-dependent deacetylase sirtuin 1) and AMPK (5'AMP-activated protein kinase) [151-154]. Several studies have demonstrated that, during neuronal infection, HSV-1 modulates the AMPK/Sirt1 axis. Particularly, AMPK is down-regulated during early infection; on the other hand, the levels of Sirt1 increase, suggesting that the AMPK/Sirt1 axis is differentially modulated by the virus during infection [155]. RSV and Quercetin activate the AMPK/Sirt1 axis and induce neuroprotective and antiviral effects in HSV-1-infected neuronal cultures [156]. Other studies have demonstrated the capacity of RSV and Quercetin to delay axonal degeneration after injury [155], to block accumulation of $A \beta$ peptide in vitro [156], to reduce BACE-1, which mediates the APP cleavage [155], and to provide protection from brain ischemia in both adult and neonatal rodents $[157,158]$. Palmitoylethanolamide (PEA), an endogenous lipid mediator is also endowed with antiinflammatory and neuroprotective effects [159]. A murine model showed that PEA counteracted the activation and inflammation seen in AD-like mouse astrocytes and promoted neuronal viability [160]. Table 3 summarizes the drugs discussed in this paragraph.

\section{Conclusions}

Reports investigating a possible role for HSV-1 in the pathogenesis of AD pathogenesis are accumulating and are making increasingly clear that HSV-1 infection is a very likely co-factor of this 
neurodegenerative disease (see Figure 2). Notably, this does not preclude a role for other microorganisms that, acting through peripheral infection and/or inducing the reactivation of latent viruses, can contribute to chronic inflammation in the brain and the consequent neuronal damage. The smoking gun is missing and much work remains to be performed to clarify the possible mechanisms of viral contribution to $A D$ neurodegeneration, and to verify whether the use of antivirals could be useful in preventing $A D$ and/or reducing its progression. It is nevertheless important to remember the story of Barry J. Marshall and J. Robin Warren who won the 2005 Nobel prize for the discovery of the bacterium Helicobacter pylori and its role in gastritis and peptic ulcer disease. The hypothesis was first published in 1984 [161], it took these scientists a long time for their discoveries to be accepted by the scientific community. Antibiotic drugs are nowadays current treatment in gastric and peptic ulcers.

\section{Expert opinion}

The discouraging results obtained in clinical trials for $A D$, trials that mainly focus on $A \beta$ accumulation and its elimination, suggest the need for alternate strategies to fight this cruel and devastating disease. Although a general erroneous idea often identifies viruses with acute damage only, many examples (e.g. HIV, measles, JCV) exist in human pathology indicating that viruses can persist in the body throughout life and can result in diseases many years after the primary infection.

A large number of evidences suggests a possible link between HSV-1 and AD, and results obtained in vitro and in animal models indicate that HSV-1 infection can result in anatomical and cellular abnormalities that resemble those seen in AD.

However, several important points must be underlined:

1) HSV-1 is a very common and widespread virus; fortunately nevertheless the majority of HSV-1infected individuals does not developed AD. HSV-1, thus, can't be the only causative factor of AD, but it is a risk factor that, among others, as genetics, inflammatory status, or other infections, can favor the onset and development of the disease. The main question within this hypothesis is if $A D$ can develop in the absence of HSV-1 i.e. whether the presence of HSV-1 is a necessary and mandatory factor in $A D$ pathogenesis. As other pathogens have been detected in brain of $A D$ subjects and the disease can also develop in HSV-1 seronegative subjects, in future it will be interesting to analyze the entire microbiome. 
2) If HSV-1 is one possible risk factor for AD, as the distribution of HSV-1 seroprevalence with age is changing, with an increased number of younger subjects susceptible to HSV infection compared to twenty years ago, we cannot exclude that this epidemiological change can have future effect on the risk of dementia. Although the outcome of infection is determined by several combined factors (i.e. genetic of the host, biology of virus, other environmental agents), to better understand this aspect it will be important to perform larger epidemiological studies and to monitor in the next years the possible change of HSV-1-associated dementia risk.

3) The presence of viral DNA in the human brain of at least a part of elderly people has been repeatedly shown in autoptic analyses, but the frequency and effects of viral reactivation in the CNS is not known and is extremely difficult to investigate. As of today it is impossible to measure HSV-1 reactivation in brain in vivo, thus no final evidences linking HSV-1 reactivation with $A D$ development can be drown. Analyses performed on CSF are an acceptable proxy of what goes in CNS, but it is unethical to think of performing repeated lumbar punctures in elderly people for research purposes, and no peripheral biomarkers of asymptomatic viral reactivation in the CNS have been identified. The development of probes specific for viral reactivation that could be used for imaging techniques and/or the identification of novel peripheral biomarkers, including pathology-specific microRNA could be an interesting way to allow noninvasive longitudinal monitoring of viral replication in brain.

4) If HSV-1 reactivation is indeed linked to the development of $A D$, then antiviral drugs should be used for its prevention. But, whom should we treat? All HSV-1 seropositive subjects or, rather only those HSV-1 infected individuals who are characterized by an unfavorable genetic or immune background or in whom a familiarity for $A D$ is known? And when should therapy be started: at the first symptoms of cognitive decline or should we consider the possibility of a life-long therapy? An intense effort to develop basic translational and clinical research needs to be envisioned to try and find a cure for $A D$, a disease whose prevalence is constantly increasing and for which no therapies are currently available.

The idea that HSV-1 infection is associated with/responsible for Alzheimer's disease has been investigated starting from the mid 80 's; this hypothesis has gained strength and has recently been supported by a string of experimental and clinical results. Many hints, thou, do not add up to a 
fully convincing proof: the smoking gun is still missing. Data stemming from a long term follow-up study of patients showed that episodic memory impairment is associated with HSV-1 infection, especially among ApoE4 carriers [162]; this leads to the design of a pilot study based on the use of valaciclovir (VALZ-Pilot, NCT02997982), an antiviral, in AD patients and MCl individuals. Results of this clinical trial, now in Phase II, should help clarifying whether antivirals can modulate the progression of cognitive decline. Bigger trials performed in larger cohorts that include different ethnic groups and take into account the variety of environmental and genetic factors suspected to be involved in the pathogenesis of $A D$ will nevertheless be needed to definitely verify whether antiviral drugs can have a preventative and/or therapeutic effect in $A D$ [see also ref.]. The unequivocal identification and characterization of those HSV-1 epitopes that elicit immune response in Alzheimer's patients, in HSV-1-infected asymptomatic individuals and in HSV-1exposed uninfected individuals, will be extremely useful in designing efficient vaccines. Finally, as it is known that HSV-1 can persist in enteric neurons as well, it will be interesting to study the effect of viral reactivation in this compartment, and to analyze if interventions aimed at modifying the microbioma could have a beneficial effects in $A D$ secondary to the prevention of HSV-1 reactivation in the gastro enteric tract.

\section{Funding}

This paper was not funded.

\section{Declaration of interest}

The authors have no relevant affiliations or financial involvement with any organization or entity with financial interest in or financial conflict with the subject matter or material discussed in the manuscript. This includes employment, consultancies, honoraria, stock ownership or options, expert testimony, grants or patents received or pending, or royalties.

\section{Reviewer disclosures}

Peer reviewers on this manuscript have no relevant financial or other relationships to disclose. 


\section{References}

Papers of special note have been highlighted as:

* of interest

** of considerable interest

1. World Alzheimer Report 2018. The state of art of dementia research: New frontiers. Alzheimer's disease international. Avalaible from: https://www.alz.co.uk/research/WorldAlzheimerReport 2018.pdf?2.

2. McKhann GM, Knopman DS, Chertkow $\mathrm{H}$, et al. The diagnosis of dementia due to Alzheimer's disease: recommendations from the National Institute on Aging-Alzheimer's Association workgroups on diagnostic guidelines for Alzheimer's disease. Alzheimers Dement 2011;7:263-269.

3. Sperling RA, Aisen PS, Beckett LA, et al. Toward defining the preclinical stages of Alzheimer's disease: recommendations from the National Institute on Aging-Alzheimer's Association workgroups on diagnostic guidelines for Alzheimer's disease. Alzheimers Demen 2011;7:280292.

4. Kumar A, Singh A, Ekavali N. A review on Alzheimer's disease pathophysiology and its management: an update. Pharmacol Rep 2015;67:195-203.

••5. Itzhaki RF, Lathe R, Balin BJ, et al. Microbes and Alzheimer's disease. J Alzheimers Dis. 2016;51(4):979-984.

$\bullet 6$. Ball MJ. Limbic predilection in Alzheimer dementia: is reactivated herpesvirus involved? Can J Neurol Sci 1982;9(3):303-306.

7. Davis LE, Johnson RT. An explanation for the localization of herpes simplex encephalitis? Ann Neurol 1979;5:2-5.

8. Jamieson GA, Maitland NJ, Wilcock GK, et al. Latent herpes simplex virus type 1 in normal and Alzheimer's disease brains. J Med Virol 1991;33:224-227.

9. Itzhaki RF, Lin WR, Shang D, et al. Herpes simplex virus type 1 in brain and risk of Alzheimer's disease. Lancet 1997;349:241-244.

10.Itzhaki RF, Wozniak MA. Herpes simplex virus type 1 in Alzheimer's disease: the enemy within. J Alzheimers Dis 2008;13:393-405.

11. Walker DG, O’Kusky JR, McGeer PL. In situ hybridization analysis for herpes simplex virus nucleic acids in Alzheimer disease. Alzheimer Dis Assoc Disord 1989;3:123-131. 
12. Olsson J, Lovheim H, Honkala E, Karhunen PJ, Elgh F, Kok EH. HSV presence in brains of individuals without dementia: the TASTY brain series. Dis Model Mech 2016;9:1349-1355. 13. Baringer JR, Pisani P. Herpes simplex virus genomes in human nervous system tissue analyzed by polymerase chain reaction. Ann Neurol 1994;36:823-829.

14. Readhead B, Haure-Mirande JV, Funk CC, et al. Multiscale Analysis of Independent Alzheimer's Cohorts Finds Disruption of Molecular, Genetic, and Clinical Networks by Human Herpesvirus. Neuron 2018;99(1):64-82.e7.

15. Alonso R, Pisa D, Fernandez-Fernandez AM, Carrasco L. Infection of Fungi and Bacteria in Brain Tissue From Elderly Persons and Patients With Alzheimer's Disease. Front Aging Neurosci 2018;10:159.

16. Roizman B, Whitley RJ. An inquiry into the molecular basis of HSV latency and reactivation. Annu Rev Microbiol 2013;67:355-374.

17. Whitley R, Kimberlin DW, Prober CG. Pathogenesis and disease. Human Herpesviruses: Biology, Therapy, and Immunoprophylaxis. Cambridge: Cambridge University Press; 2007. 18. World Health Organization 2017. Herpes simplex virus. Avalaible from: http://www.who.int/mediacentre/factsheets/fs400/en/ 19. Looker KJ, Magaret AS, May MT, et al. Global and Regional Estimates of Prevalent and Incident Herpes Simplex Virus Type 1 Infections in 2012. PLoS One 2015;10(10):e0140765. 20. Roizman B, Campadelli-Fiume G. Alphaherpes viral genes and their functions. Immunoprophylaxis Cambridge: Cambridge University Press 2007;6.

21. Campadelli-Fiume G, Menotti L. Entry of alphaherpesviruses into the cell. Human Herpesviruses: Biology, Therapy, and Immunoprophylaxis. Cambridge: Cambridge University Press; 2007.

22. Kelly BJ, Fraefel C, Cunningham AL, et al. Functional roles of the tegument proteins of herpes simplex virus type 1. Virus Res 2009;145(2):173-186.

23. Weed DJ, Nicola AV. Herpes simplex virus Membrane Fusion. Adv Anat Embryol Cell Biol 2017;223:29-47.

24. Di Giovine P, Settembre EC, Bhargava AK, et al. A Structure of herpes simplex virus glycoprotein D bound to the human receptor nectin-1. PLoS Patog 2011;7:1-13.

25. Campadelli-Fiume G, Collins-McMillen D, Gianni T, et al. Integrins as Herpesvirus Receptors and Mediators of the Host Signalosome. Annu Rev Virol 2016;3(1):215-236.

26. Dohner K, Binz A, Glass M, et al. Uncoupling uncoating of herpes simplex virus genomes 
from their nuclear import and gene expression J Virol. 2011;85(9):4271-4283.

27. Roizman B, Zhou G, Du T. Checkpoints in productive and latent infections with herpes simplex virus 1: conceptualization of the issues. J Neurovirol 2011;17(6):512-517.

28. Sampath P, Deluca NA. Binding of ICP4, TATA-binding protein, and RNA polymerase II to herpes simplex virus type 1 immediate-early, early, and late promoters in virus-infected cells. J Virol 2008;82(5):2339-49.

29. Sandri-Goldin RM. The many roles of the highly interactive HSV protein ICP27, a key regulator of infection. Future Microbiol 2011;6(11):1261-1277.

30. Maruzuru Y, Shindo K, Liu Z, et al. Role of herpes simplex virus 1 immediate early protein ICP22 in viral nuclear egress. J Virol 2014; 88:7445-7454.

31. Herbring V, Baucker A, Trowitzsch S, et al. A dual inhibition mechanism of herpesviral ICP47 arresting a conformationally thermostable TAP complex. Sci Rep 2016;6:36907.

32. Gu H. Infected cell protein 0 functional domains and their coordination in herpes simplex virus replication. World J Virol 2016;5(1):1-13.

33. Miranda-Saksena M, Denes CE, Diefenbach RJ, et al. Infection and Transport of Herpes Simplex Virus Type 1 in Neurons: Role of the Cytoskeleton. Viruses 2018;10(2).

34. Koyuncu OO, Hogue IB, Enquist LW. Virus infections in the nervous system. Cell Host Microbe 2013;13(4):379-393.

35. Bloom DC, Giordani NV, Kwiatkowski DL. Epigenetic regulation of latent HSV-1 gene expression. Biochim Biophys Acta 2010;1799: 246-256.

36. Carpenter D, Hsiang C, Brown DJ, et al. Stable cell lines expressing high levels of the herpes simplex virus type 1 LAT are refractory to caspase 3 activation and DNA laddering following cold shock induced apoptosis. Virology 2007;369(1):12-18.

37. Valyi-Nagy T, Deshmane S, Dillner A, et al. Induction of cellular transcription factors in trigeminal ganglia of mice by corneal scarification, herpes simplex virus type 1 infection, and explantation of trigeminal ganglia. J Virol 1991;65:4142-4152.

38. Miranda-Saksena M, Boadle RA, Aggarwal A, et al. Herpes simplex virus utilizes the large secretory vesicle pathway for anterograde transport of tegument and envelope proteins and for viral exocytosis from growth cones of human fetal axons. J Virol 2009;83(7):3187-3199. 39. Nishiyama Y. Herpes simplex virus gene products: the accessories reflect her lifestyle well. Rev Med Virol 2004;14(1):33-46. 
40. Tognarelli El, Palomino TF, Corrales N, et al. Herpes Simplex Virus Evasion of Early Host Antiviral Responses. Front Cell Infect Microbiol 2019;9:127.

41. Carpenter D, Hsiang C, Jiang X, et al. The herpes simplex virus type 1 (HSV-1) latencyassociated transcript (LAT) protects cells against cold-shock-induced apoptosis by maintaining phosphorylation of protein kinase B (AKT). J Neurovirol 2015;21(5):568-575.

42. Shen W, Sa e Silva M, Jaber T, et al. Two small RNAs encoded within the first 1.5 kilobases of the herpes simplex virus type 1 latency-associated transcript can inhibit productive infection and cooperate to inhibit apoptosis. J Virol 2009;83:9131-9139.

43. Kato A, Kawaguchi Y. Us3 Protein Kinase Encoded by HSV: The Precise Function and Mechanism on Viral Life Cycle. Adv Exp Med Biol 2018;1045:45-62.

44. Benetti L, Roizman B. Herpes simplex virus protein kinase US3 activates and functionally overlaps protein kinase A to block apoptosis. Proc Natl Acad Sci U S A. 2004;101(25):94119416.

45. Benetti L, Roizman B. In transduced cells, the US3 protein kinase of herpes simplex virus 1 precludes activation and induction of apoptosis by transfected procaspase 3. J Virol 2007;81(19):10242-10248.

46. Jerome KR, Fox R, Chen Z, et al. Herpes simplex virus inhibits apoptosis through the action of two genes, Us5 and Us3. J Virol 1999;73(11):8950-8957.

47. Jerome KR, Chen Z, Lang R, et al. HSV and glycoprotein J inhibit caspase activation and apoptosis induced by granzyme B or Fas. J Immunol 2001;167(7):3928-3935.

48. Ma Y, He B. Recognition of herpes simplex viruses: toll-like receptors and beyond. J Mol Biol 2014;426(6):1133-1147.

49. Zhang SY, Jouanguy E, Ugolini S, et al. TLR3 deficiency in patients with herpes simplex encephalitis. Science 2007;317:1522-1527.

50. Johnson KE, Chikoti L, Chandran B. Herpes Simplex Virus 1 Infection Induces Activation and Subsequent Inhibition of the IFI16 and NLRP3 Inflammasomes. J Virol 2013;87:5005-5018.

51. Veeranki S, Choubey D. Interferon-inducible p200-family protein IFI16, an innate immune sensor for cytosolic and nuclear double-stranded DNA: Regulation of subcellular localization. Mol Immunol 2012;49:567-571.

52. Johnson KE, Bottero V, Flaherty S, et al. IFI16 restricts HSV-1 replication by accumulating on the hsv-1 genome, repressing HSV-1gene expression, and directly or indirectly modulating histone modifications. PLoS Pathog 2014;10(11):e1004503. 
53. Zhang J, Liu H, Wei B. Immune response of T cells during herpes simplex virus type 1 (HSV1) infection. J Zhejiang Univ Sci B 2017;18(4):277-288.

54. Wu X, Wu P, Shen Y, et al. CD8(+) Resident Memory T Cells and Viral Infection. Front Immunol 2018;9:2093.

55. St Leger AJ, Hendricks RL. CD8+ T cells patrol HSV-1-infected trigeminal ganglia and prevent viral reactivation. J Neurovirol 2011;17(6):528-534.

56. Kalantari-Dehaghi M, Chun S, Chentoufi AA, et al. Discovery of potential diagnostic and vaccine antigens in herpes simplex virus 1 and 2 by proteome-wide antibody profiling. J Virol 2012;86(8):4328-39.

57. Clementi N, Cappelletti F, Criscuolo E, et al. Role and potential therapeutic use of antibodies against herpetic infections. Clin Microbiol Infect 2017;23(6):381-386.

58. Posavad CM, Remington M, Mueller DE, et al. Detailed characterization of T cell responses to herpes simplex virus-2 in immune seronegative persons. J Immunol 2010;184:3250-3259. 59. Jing L, Laing KJ, Dong L, et al. Extensive CD4 and CD8 T Cell Cross-Reactivity between Alphaherpesviruses. J Immunol 2016;196(5):2205-2218.

60. Johnston C, Gottlieb SL, Wald A. Status of vaccine research and development of vaccines for herpes simplex virus. Vaccine 2016;34(26):2948-2952.

61. Su C, Zhan G, Zheng C. Evasion of host antiviral innate immunity by HSV-1, an update. Virol J 2016;13:38.

62. Alexander DE, Leib DA. Xenophagy in herpes simplex virus replication and pathogenesis. Autophagy 2008;4:101-103.

63. Mulvey M, Camarena V, Mohr I. Full resistance of herpes simplex virus type 1-infected primary human cells to alpha interferon require both the Us11 and $\gamma 134.5$ gene products. J Virol 2004;78:10193-10196.

64. Peng $W$, Henderson $G$, Inman $M$, et al. The locus encompassing the latency-associated transcript of herpes simplex virus type 1 interferes with and delays interferon expression in productively infected neuroblastoma cells and trigeminal ganglia of acutely infected mice. J Virol 2005;79:6162-6171.

65. Imai T, Koyanagi N, Ogawa R, et al. Us3 kinase encoded by herpes simplex virus 1 mediates downregulation of cell surface major histocompatibility complex class I and evasion of CD8+ T cells. PLoS One 2013;8:e72050. 
66. Rao P, Pham HT, Kulkarni A, et al. Herpes simplex virus 1 glycoprotein B and US3 collaborate to inhibit CD1d antigen presentation and NKT cell function. J Virol 2011;85(16):8093-8104.

67. Shives KD, Tyler KL, Beckham JD. Molecular mechanisms of neuroinflammation and injury during acute viral encephalitis. J Neuroimmunol 2017;308:102-111.

68. Lokensgard JR, Hu S, Sheng W, et al. Robust expression of TNF- $\alpha$, IL-1 $\beta$, RANTES, and IP-10 by human microglial cells during nonproductive infection with herpes simplex virus. J Neurovirol 2001;7:208-219.

69. Nicoll MP, Proenca JT, Efstathiou S. The molecular basis of herpes simplex virus latency. FEMS Microbiol Rev 2012;26:684-705.

70. Stowe RP, Peek MK, Cutchin MP, Goodwin JS. Reactivation of herpes simplex virus type 1 is associated with cytomegalovirus and age. J Med Virol 2012;84(11):1797-1802.

71. Martin C, Aguila B, Araya P, et al. Inflammatory and neurodegeneration markers during asymptomatic HSV-1 reactivation. J Alzheimers Dis 2014;39:849-859.

72. Michael BD, Griffiths MJ, Granerod J, et al. The interleukin-1 balance during encephalitis is associated with clinical severity, blood-brain barrier permeability, neuroimaging changes, and disease outcome. J Infect Dis 2016;213:1651-1660.

73. Aurelius $E$, Andersson B, Forsgren $M$, et al. Cytokines and other markers of intrathecal immune response in patients with herpes simplex encephalitis. J Infect Dis 1994;170:678-681. 74. Knickelbein JE, Khanna KM, Yee MB, et al. Noncytotoxic lytic granule-mediated CD8+ T cell inhibition of HSV-1 reactivation from neuronal latency. Science 2008;322(5899):268-271. 75. Yu W, Geng S, Suo Y, et al. Critical Role of Regulatory T Cells in the Latency and StressInduced Reactivation of HSV-1. Cell Rep 2018;25:2379-2389.

-76. Dervillez X, Qureshi H, Chentoufi AA, et al. Asymptomatic HLA-A*02:01-restricted epitopes from herpes simplex virus glycoprotein B preferentially recall polyfunctional CD8+ T cells from seropositive asymptomatic individuals and protect HLA transgenic mice against ocular herpes. J Immunol 2013;191:5124-5138.

77. Saresella M, Marventano I, Calabrese E, et al. A complex proinflammatory role for peripheral monocytes in Alzheimer's disease. J Alzheimers Dis 2014;38(2):403-413.

78. Saresella M, La Rosa F, Piancone F, et al. The NLRP3 and NLRP1 inflammasomes are activated in Alzheimer's disease. Mol Neurodegener 2016;11:23.

79. Togo T, Akiyama H, Iseki E et al. Occurrence of T cells in the brain of Alzheimer's disease 
and other neurological diseases. J Neuroimmunol 2002;124:83-92.

80. De Chiara G, Piacentini R, Fabiani M, et al. Recurrent herpes simplex virus-1 infection induces hallmarks of neurodegeneration and cognitive deficits in mice. PLoS Pathog 2019;15(3):e1007617.

81. Agostini S, Mancuso R, Baglio F, et al. A protective role for herpes simplex virus type-1specific humoral immunity in Alzheimer's disease. Expert Rev Anti Infect Ther 2017;15(2):8991.

82. Letenneur L, Peres K, Fleury H et al. Seropositivity to herpes simplex virus antibodies and risk of Alzheimer's disease: a population-based cohort study. PLoS One 2008;3(11):e3637. 83. Mancuso R, Baglio F, Cabinio M, et al. Titers of herpes simplex virus type 1 antibodies positively correlate with grey matter volume in Alzheimer's disease.J Alzheimers Dis 2014;38:741-745.

84. Mancuso R, Baglio F, Agostini S, et al. Relationship between herpes simplex virus-1-specific antibody titers and cortical brain damage in Alzheimer's disease and amnestic mild cognitive impairment Front Aging Neurosci 2014;6:285.

85. Agostini S, Mancuso R, Baglio F, et al. Lack of evidence for a role of HHV-6 in the pathogenesis of Alzheimer's disease. J Alzheimers Dis 2015;49(1):229-235.

86. Dorshkind K, Montecino-Rodriguez E, Signer RA. The ageing immune system: is it ever too old to become young again? Nat Rev Immunol 2009;9(1):57-62.

87. Montagne A, Barnes SR, Sweeney MD, et al. Blood-brain barrier breakdown in the aging human hippocampus. Neuron 2015;85(2):296-302.

88. Kobayashi N, Nagata T, Shinagawa S et al. Increase in the IgG avidity index due to herpes simplex virus type 1 reactivation and its relationship with cognitive function in amnestic mild cognitive impairment and Alzheimer's disease. Biochem. Biophys Res Commun 2013;430(3):907-911.

89. Agostini S, Mancuso R, Baglio F, et al. High avidity HSV-1 antibodies correlate with absence of amnestic Mild Cognitive Impairment conversion to Alzheimer's disease. Brain Behav Immun 2016;58:254-260.

90. Agostini S, Mancuso R, Hernis A, et al. HSV-1-Specific IgG Subclasses Distribution and Serum Neutralizing Activity in Alzheimer's Disease and in Mild Cognitive Impairment. J Alzheimers Dis 2018;63(1):131-138. 
91. Vidarsson G, Dekkers G, Rispens T. IgG subclasses and allotypes: From structured to effector functions. Front Immunol 2014;5:520.

92. Dubin G, Socolof E, Frank I, et al. Herpes simplex virus type 1 Fc receptor protects infected cells form antibody-dependent cellular cytotoxicity. J Virol 1991;65:7046- 7050.

93. Agrawal P, Nawadkar R, Ojha H, et al. Complement Evasion Strategies of Viruses: An Overview. Front Microbiol 2017;8:1117.

94. Johansson PJ, Ota T, Tsuchiya N, et al. Studies of protein A and herpes simplex virus-1 induced FC-gamma binding specifities. Different binding patterns for IgG3 from Caucasian and Oriental subjects. Immunology 1994;83:631-638.

95. Iijima N, Iwasaki A. Access of protective antiviral antibody to neuronal tissues requires CD4 T-cell help. Nature 2016;533(7604):552-556.

96. Carbone I, Lazzarotto T, Ianni M, Porcellini E, Forti P, Masliah E, et al. Herpes virus in Alzheimer's disease: relation to progression of the disease. Neurobiol Aging 2014;35:122-129. 97. Mattson MP. Pathways towards and away from Alzheimer's disease. Nature 2004;430(7000):631-639.

98. Wozniak MA, Itzhaki RF, Shipley SJ, et al. Herpes simplex virus infection causes cellular $\beta$ amyloid accumulation and secretase upregulation. Neurosci Lett 2007;429:95-100.

99. De Chiara G, Marcocci ME, Civitelli L, et al. APP processing induced by herpes simplex virus type 1 (HSV-1) yelds several APP fragments in human and rat neuronal cells. PloS One 2010;5:e13989.

100. Piacentini R, Civitelli L, Ripoli C, et al. HSV-1 promotes Ca2+-mediated APP phosphorylation and $A \beta$ accumulation in rat cortical neurons. Neurbiol Aging 2011;32:2323.e13-2323-e26.

101. Lopez JR, Lyckman A, Oddo S, et al. Increased intraneuronal resting [Ca2+] in adult Alzheimer's disease mice. J Neurochem 2008;105:262-271.

102. Emilsson L, Saetre P, Jazin E. Alzheimer's disease: mRNA expression profiles of multiple patients show alterations of genes involved with calcium signaling. Neurobiol Dis 2006;21:618625.

103. Cribbs DH, Azizeh BY, Cotman CW, et al. Fibril formation and neurotoxicity by a herpes simplex virus glycoprotein B fragment with homology to the Alzheimer's A beta peptide. Biochemistry 2000;39:5988-5994. 
104. Benboudjema L, Mulvey M, Gao Y, et al. Association of the herpes simplex virus type 1 Us11 gene product with the cellular kinesin light-chain-related protein PA1 results in the redistribution of both polypeptides. J Virol 2003;77:9192-9203.

105. Satpute-Krishnan P, DeGiorgis JA, Bearer EL. Fast anterograde transport of herpes simplex virus: role for the amyloid precursor protein of Alzheimer's disease. Aging Cell 2003;25:419429.

106. Robinson SR, Bishop GM. Abeta as bioflocculant: implications for the amyloid hypothesis of Alzheimer's disease. Neurobiol Aging 2002;23(6):1051-1072.

107. Bourgade K, Dupuis G, Frost EH, Fulop T. Anti-viral properties of amyloid- $\beta$ peptides. J Alzheimers Dis 2016;54(3):859-878.

108. Spillantini MG, Goedert M. Tau pathology and neurodegeneration. Lancet Neurol 2013;12(6):609-622.

109. Chun W, Johnson GV. The role of tau phosphorylation and cleavage in neuronal cell death. Front Biosci 2007;12:733-756.

110. Zambrano A, Solis L, Salvadores N, et al. Neuronal cytoskeletal dynamic modification and neurodegeneration induced by infection with herpes simplex virus type 1. J Alzheimers Dis 2008;14:259-269.

111. Alvarez G, Aldudo J, Alonso M, et al. Hepres simplex virus type 1 induces nuclear accumulation of hyperphosphorylated tau in neuronal cells. J Neurosci Res 2012;90:10201029.

112. Wozniak MA, Frost AL, Itzhaki RF. Alzheimer's disease-specific tau phosphorylation is induced by herpes simplex virus type 1. J Alzheimers Dis 2009;16:341-350.

113. Nixohn RA. Autophagy, amyloidogenesis and Alzheimer's disease. J Cell Sci 2007;120:4081-4091.

114. Santana S, Bullido MJ, Recuero M, et al. Herpes simplex virus type 1 induces an incomplete autophagic response in human neuroblastoma cells. J Alzheimers Dis 2012;30:815831.

115. Santana S, Recuero M, Bullido MJ, et al. Herpes simplex virus type 1 induces the accumulation of intracellular $\beta$-amyloid in autophagic compartments and the inhibition of the non-amyloidogenic pathway in human neuroblastoma cells. Neurobiol Aging 2012;33:430.e19430.e33. 
116. Scheff SW, Ansari MA, Mufson EJ. Oxidative stress and hippocamap synaptic protein levels in elderly cognivetively intact individuals with Alzheimer's disease pathology. Neurobiol Aging 2016;42:1-12.

117. Nucci C, Palamara AT, Ciriolo MR, et al. Imbalance in corneal redox state during herpes simplex virus 1-induced keratitis in rabbits. Effectiveness of exogenous glutathione supply. Exp Eye Res 2000;70:215-220.

118. Meyding-Lamadè U, Haas J, Lamadè W, et al. Herpes simplex virus encephalitis: long-term comparative study of viral load and the expression of immunologic nitric oxide synthase in mouse brain tissue. Neurosci Lett 1998;244:9-12.

119. Santana S, Sastre I, Recuero M. Oxidative stress enhances neurodegeneration markers induced by herpes simplex virus type 1 infection in human neuroblastoma cells. PLoS One 2013;8:e75842.

120. Elfawy HA, Das B. Crosstalk between mitochondrial dysfunction, oxidative stress, and age related neurodegenerative disease: etiologies and therapeutic strategies. Life Sci 2019;218:165-184.

121. Kramer T, Enquist LW. Aherpesvirus infection disrupts mitochondrial transport in neurons. Cell Host Microbe 2012;11:504-514.

122. Saffran HA, Pare JM, Corcoran JA, et al. Herpes simplex virus eliminates host mitochondrial DNA. EMBO Rep 2007;8:188-193.

123. Huang Y, Mahley RW. Apolipoprotein E: structure and function in lipid metabolism, neurobiology, and Alzheimer's diseases. Neurobiol Dis. 2014;72:3-12.

124. Guzman-Sanchez F, Valdivieso F, Burgos JS. Aging-related neurostructural, neuropathological, and behavioral changes associated with herpes simplex type 1 brain infection in mice. J Alzheimers Dis 2012;30:779-790.

125. Itzhaki RF, Wozniak MA. Herpes simplex virus type 1, apolipoprotein E, and cholesterol: a dangerous liaison in Alzheimer's disease and other disorders. Prog Lipid Res 2006;45(1):73-90. 126. Lambert JC, Zelenika D, Hiltunen M, et al. Evidence of the association of BIN1 and PICALM with the AD risk in contrasting European population. Neurobiol Aging 2011;32:756.e11756.e15.

127. Porcellini E, Carbone I, lanni M, et al. Alzheimer's disease gene signature says: beware of brain viral infection. Immun Ageing 2010;7:16.

128. Tschopp J, Chonn A, Hertig S, et al. Clusterin, the human apolipoprotein and complement 
inhibitor, binds to complement C7, C8 beta, and the b domain of C9. J Immunol 1993;151:2159-2165.

129. Humer HP, Wang Y, Garred P, et al. Herpes simplex virus glycoprotein C: molecular mimicry of complement regulatory proteins by a viral protein. Immunology 1993;79:639-647. 130. Papassotiropoulos A, Lambert JC, Wavrant-De Vrieze F, et al. Cholesterol 25-hydroxylase on chromosome 10q is a susceptibility gene for sporadic Alzheimer's disease. Neurodegener Dis $2005 ; 2: 233-241$.

131. Liu SY, Aliyari R, Chikere K, et al. Interferon-inducible cholesterol-25-hydroxylase broadly inhibits viral entry by production of 25-hydroxhycholesterol. Immunity 2013;38:92-105. 132. Lathe R, Sapronova A, Kotelevtsev Y. Atherosclerosis and Alzheimer - disease with a common cause? Inflammation, oxysterols, vasculature. BMC Geriatr 2014;14:36.

133. Costa AS, Agostini S, Guerini FR, et al. Modulation of immune responses to herpes simplex virus type 1 by IFNL3 and IRF7 polymorphisms: a study in Alzheimer's disease. J Alzheimers Dis 2017;60:1055-1063.

134. Rathore N, Ramani SR, Pantua H, et al. Paired immunoglobulin-like type 2 receptor alpha G78R variant alters ligand binding and confers protection to Alzheimer's disease. PLoS Genet 2018;14:e1007427.

135. Satoh T, Arii J, Suenaga T, et al. PILRalpha is a herpes simplex virus-1 entry coreceptor that associaters with glycoprotein B. Cell 2008;132:935-944.

136. Arosio B, Trabattoni D, Galimberti L, et al. Interleukin-10 and interleukin-6 gene polymorphisms are risk factors for Alzheimer's disease. Neurobiol Aging 2004;25(8):10091015.

137. Sing R, Kumar A, Creery WD, et al. Dysregulated expression of IFN-gamma and IL-10 and impaired IFN-gamma-mediated responses at different disease stages in patients with genital herpes simplex virus-2 infection. Clin Exp Immunol 2003;133(1):97-107.

138. Cummings JL, Zhong K. Repackaging FDA-approved drugs for degenerative diseases: promises and challenges. Expert Rev Clin Pharmacol 2014;7(2):161-165.

139. Mielke MM, Leoutsakos JM, Corcoran CD, et al. Effects of Food and Drug Administrationapproved medications for Alzheimer's disease on clinical progression. Alzheimers Dement 2012;8(3):180-187.

140. Wozniak MA, Frost AL, Preston CM, et al. Antivirals reduce the formation of key Alzheimer's disease molecules in cell cultures acutely infected with Herpes simplex virus type 
1. PLoS One 2011;6:e25152.

$\bullet$ 141. Tzeng NS, Chung CH, Lin FH, et al. Anti-herpetic medications and reduced risk of dementia in patients with herpes simplex virus infections - a nationwide, population - based cohort study in Taiwan. Neurotherapeutics 2018;15(2):417-429.

•142. Tsai MC, Cheng WL, Sheu JJ, et al. Increased risk of dementia following herpes zoster ophthalmicus. PLoS One 2017;12(11):e0188490.

143. Chen VC, Wu SI, Hunag KY, et al. Herpes zoster and dementia: a nationwide populationbased cohort study. J Clin Psychiatry 2018;79(1).

144. Hussain G, Zhang L, Rasul A, et al. Role of Plant-Derived Flavonoids and Their Mechanism in Attenuation of Alzheimer's and Parkinson's Diseases: An Update of Recent Data. Molecules 2018;23:814.

145. Zhang X, Wang G, Gurley EC, et al. Flavonoid apigenin inhibits lipopolysaccharide-induced inflammatory response through multiple mechanisms in Macrophages. PLoS One 2014;9(9):e107072.

146. Kim H, Bang OY, Jung MW, et al. Neuroprotective effects of estrogen against beta-amyloid toxicity are mediated by estrogen receptors in cultured neuronal cells. Neurosci Lett 2001;302(1):58-62.

147. Wang $\mathrm{H}$, Wang $\mathrm{H}$, Cheng $\mathrm{H}$, et al. Ameliorating effect of luteolin on memory impairment in an Alzheimer's disease model. Mol Med Rep 2016;13:4215-4220.

148. Choi Y, Choi JH, Lee JY, et al. Apigenin protects HT22 murine hippocampal neuronal cells against endoplasmic reticulum stress-induced apoptosis. Neurochem Int 2010;57:143-152. 149. Du K, Liu M, Zhong X, et al. Epigallocatechin Gallate Reduces Amyloid $\beta$-Induced Neurotoxicity via Inhibiting Endoplasmic Reticulum Stress-Mediated Apoptosis. Mol Nutr Food Res 2018;62(8):e1700890.

150. Thummayot S, Tocharus C, Suksamrarn A, et al. Neuroprotective effects of cyanidin against $A \beta$-induced oxidative and ER stress in SK-N-SH cells. Neurochem Int 2016;101:15-21. 151. Sohanaki H, Baluchnejadmojarad T, Nikbakht F, et al. Pelargonidin improves memory deficit in amyloid $325-35$ rat model of Alzheimer's disease by inhibition of glial activation, cholinesterase, and oxidative stress. Biomed Pharmacother 2016;83:85-91.

152. Martin C, Leyton L, Arancibia Y, et al. Modulation of the AMPK/Sirt1 axis during neuronal infection by herpes simplex virus type 1. J Alzheimers Dis 2014;42:301-312.

153. Salminen A, Hyttinen JM, Kaarniranta K. AMP-activated protein kinase inhibits NF-KB 
signaling and inflammation: Impact on healthspan and lifespan. J Mol Med 2011;89:667-676. 154. Faith SA, Sweet TJ, Bailey E, et al. Resveratrol suppresses nuclear factor-kappaB in herpes simplex virus infected cells. Antivir Res 2006;72:242-251.

155. Araki T, Sasaki Y, Milbrandt J, Increased nuclear NAD biosynthesis and SIRT1 activation prevent axonal degeneration. Science 2004;305:1010-1013.

156. Han YS, Zheng WH, Bastianetto S, et al. Neuropro-tective effects of resveratrol against beta-amyloid-induced neurotoxicity in rat hippocampal neurons: involvement of protein kinase C. Br J Pharmacol 2004;141:997-1005.

157. Wang Q, Xu J, Rottinghaus GE, et al. Resveratrol protects against global cerebral ischemic injury in gerbils. Brain Res 2002;958:439-447.

158. Sabogal-Guaqueta AM, Munoz-Manco JI, Ramirez-Pineda JR, et al. The Flavonoid Quercetin Ameliorates Alzheimer's Disease Pathology and Protects Cognitive and Emotional Function in Aged Triple Transgenic Alzheimer's Disease Model Mice. Amsterdam: Elsevier Ltd; 2015.

159. Scuderi C, Stecca C, Valenza M, et al. Palmitoylethanolamide controls reactive gliosis and exerts neuroprotective functions in a rat model of Alzheimer's disease. Cell Death Dis 2014;5:e1419.

160. Bronzuoli MR, Facchinetti R, Steardo L Jr, et al. Palmitoylethanolamide Dampens Reactive Astrogliosis and Improves Neuronal Trophic Support in a Triple Transgenic Model of Alzheimer's Disease: In Vitro and In Vivo Evidence. Oxid Med Cell Longev 2018;2018:4720532. 161. Marshall BJ, Warren JR. Unidentified curved bacilli in the stomach of patients with gastritis and peptic ulceration. Lancet 1984;1(8390):1311-1315.

162. Lovheim H, Norman T, Weidung B, et al. Herpes simplex virus, APOE\&4, and cognitive decline in old age: results from the betula cohort, J Alzheimers Dis 2019;67(1):211-220. 163. You Y, Cheng AC, Wang MS, et al. The suppression of apoptosis by $\alpha$-herpesvirus. Cell Death Dis 2017;8(4):e2749.

164. Yu X, He S. The interplay between human herpes simplex virus infection and the apoptosis and necroptosis cell death pathways. Virol J 2016;13:77.

165. Hagglund R, Munger J, Poon AP, et al. U(S)3 protein kinase of herpes simplex virus 1 blocks caspase 3 activation induced by the products of $U(S) 1.5$ and $U(L) 13$ genes and modulates expression of transduced $\mathrm{U}(\mathrm{S}) 1.5$ open reading frame in a cell type-specific manner. J Virol 2002;76(2):743-754. 
166. Gill D, Glidden M, Dean R. Unusual side effect of acyclovir: bradycardia. Am J Emerg Med 2017;35(3):525.e3-525.e4.

167. Raborn GW, Martel AY, Lassonde M, et al. Effective treatment of herpes simplex labialis with penciclovir cream: combined results of two trials. J Am Dent Assoc 2002;133(3):303-309. 168. Andrei G, Topalis D, De Schutter T, et al. Insights into the mechanism of action of cidofovir and other acyclic nucleoside phosphonates against polyomaand papillomaviruses and non-viral induced neoplasia. Antiviral Res 2015;114:21-46.

169. Yamamoto T, Maruyama Y, Ohashi N, et al. Hypophosphatemia predicts a failure to recover from adefovir-related renal injury after dose reduction in lamivudine-resistant hepatitis B patients. Hepatol Res 2017;47(12):1272-1281.

170. Sansone R, Ottaviani JI, Rodriguez-Mateos A, et al. Methylxanthines enhance the effects of cocoa flavanols on cardiovascular function: randomized, double-masked controlled studies. Am J Clin Nutr 2017;105(2):352-360.

171. Qin Y, Zhai Q, Li Y, et al. Cyanidin-3-O-glucoside ameliorates diabetic nephropathy through regulation of glutathione pool. Biomed Pharmacother 2018;103:1223-1230. 


\section{Figure Legend}

Figure 1: A schematic representation of the HSV-1 structure with lipid membrane envelope with viral surface glycoproteins, tegument layer containing viral proteins, icosahedral capsid shell and linear double-stranded DNA, is shown.

Figure 2: HSV-1 lytic infection in the epithelial cells, the process that the virus follows to infect the sensory ganglion, is shown. Retrograde transport from the sensory nerve terminus to the neuronal cell body is also shown. Factors disrupting the homeostasis that maintains the latency state results in HSV-1 reactivation; HSV-1 lytic genes in particular are reactivated. Note that sensory ganglion projects two processes: one in the epithelial tissue, the other in the brain. Newly replicated virions traffic back by anterograde axonal transport mechanisms, to re-establish infection at epithelial tissues or brain. HSV-1 enters the brains of elderly people as their immune system declines with age could contribute to the development of AD. 
Table 1: Summary of principal HSV-1 gene products with anti-apoptotic function.

\begin{tabular}{|c|c|c|c|c|}
\hline & Genes product & Role & Effects & References \\
\hline 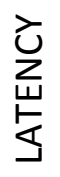 & $\begin{array}{l}\text { LAT } \\
\text { (Latency- } \\
\text { associated } \\
\text { transcript) }\end{array}$ & $\begin{array}{l}\text { Enhances the establishment of } \\
\text { latency } \\
\text { Protect the host cells from } \\
\text { apoptosis }\end{array}$ & $\begin{array}{l}\text { Inhibits apoptosis blocking GrB } \\
\text { Modulates Bad-Bax }\end{array}$ & [163] \\
\hline \multirow{4}{*}{ 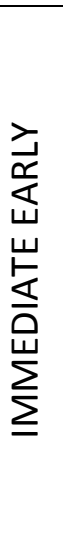 } & ICP4 & $\begin{array}{l}\text { Regulates the gene expression } \\
\text { cascade which controls viral } \\
\text { infection. } \\
\text { Anti-apoptotic }\end{array}$ & Inhibits apoptosis & 4] \\
\hline & ICP27 & $\begin{array}{l}\text { Multifunctional regulatory protein } \\
\text { Pro and anti-apoptotic }\end{array}$ & $\begin{array}{l}\text { Inhibits apoptosis by NFkB } \\
\text { JNk- Bcl-2- Bax-Bid }\end{array}$ & {$[163]$} \\
\hline & ICP 22 & $\begin{array}{l}\text { Regulator of viral gene expression } \\
\text { Promote and Inhibits apoptosis }\end{array}$ & $\begin{array}{l}\text { Inhibits Caspase 8-9 } \\
\text { AKT- NFkB }\end{array}$ & {$[165]$} \\
\hline & ICPO & Anti-apoptotic & $\begin{array}{l}\text { Inhibits caspase } 8 \\
\text { Inhibits apoptosis TNF-a }\end{array}$ & [164] \\
\hline \multirow{3}{*}{ 㟶 } & $\begin{array}{l}\text { US3 } \\
\text { (Tegument } \\
\text { Protein) }\end{array}$ & $\begin{array}{l}\text { Regulates the biological function of } \\
\text { the virus and the host cells } \\
\text { Anti-apoptotic }\end{array}$ & $\begin{array}{l}\text { Inhibits apoptosis phosphorylating } \\
\text { BAD } \\
\text { Inhibits Caspase } 3 \\
\text { Bcl2-AKT-BAX-BAD NFkB }\end{array}$ & {$[40,163]$} \\
\hline & $\begin{array}{l}\text { US5 (gJ) } \\
\text { (Envelope) }\end{array}$ & Anti-apoptotic & $\begin{array}{l}\text { Inhibits Fas } \\
\text { Caspase } 3-8\end{array}$ & [163] \\
\hline & $\begin{array}{l}\text { US6 (gD) } \\
\text { (Envelope) }\end{array}$ & Anti-apc & Inhibits by Fas-NFkB & {$[163,164]$} \\
\hline
\end{tabular}


Table 2: Summary of the principal HSV-1 proteins involved in immunoevasion.

\begin{tabular}{|c|c|c|c|c|}
\hline Phase & Gene product & ORFs & Host target & Inhibited host mechanism \\
\hline \multirow{10}{*}{ 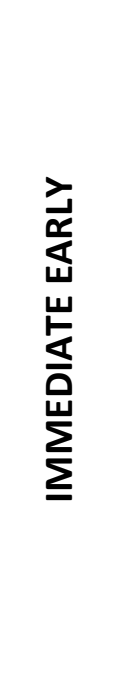 } & \multirow{7}{*}{ ICPO } & \multirow{7}{*}{ RL2 } & MyD88 & TLRs signaling/IFN response \\
\hline & & & TIRAP & TLRs signaling/IFN response \\
\hline & & & p65 & NF-kB signaling/IFN response \\
\hline & & & STING & DNA sensor signaling /IFN response \\
\hline & & & IFI16 & inflammasome \\
\hline & & & DNA PK & DNA damage response \\
\hline & & & ND10 /Sp100 nuclear bodies & chromatin epigenetic regulation \\
\hline & \multirow[t]{2}{*}{ ICP27 } & \multirow[t]{2}{*}{ UL54 } & IRF3 & TLRs signaling/IFN response \\
\hline & & & STAT1 & JAK/STAT signaling/IFN response \\
\hline & ICP47 & US12 & TAP & MHC-I antigen presentation \\
\hline \multirow[b]{2}{*}{ 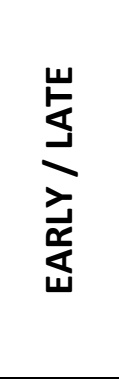 } & tegument protein & UL36USP & TRAF3 & TLRs signaling/IFN response \\
\hline & Vhs & UL41 & $\begin{array}{l}\text { mRNA host } \\
\text { IRF7 } \\
\text { JAK/STAT signaling } \\
\text { Viperin } \\
\text { ZAP } \\
\text { Tetherin }\end{array}$ & $\begin{array}{l}\text { host translational arrest } \\
\text { TLRs signaling/IFN response } \\
\text { IFN response } \\
\text { interferon-stimulated genes } \\
\text { interferon-stimulated genes } \\
\text { interferon-stimulated genes }\end{array}$ \\
\hline \multirow{16}{*}{$\underset{\square}{\frac{\omega}{5}}$} & \multirow{4}{*}{ US11 } & \multirow{4}{*}{ US11 } & RIG-1 & RLRs signaling/IFN response \\
\hline & & & MDA5 & RLRs signaling/IFN response \\
\hline & & & 2'5'OAS & interferon-stimulated genes \\
\hline & & & PKR & interferon-stimulated genes \\
\hline & \multirow{3}{*}{ ICP34.5 } & \multirow{3}{*}{ RL1 } & TBK1 & TLRs signaling/IFN response \\
\hline & & & Beclin & autophagy \\
\hline & & & PKR & NF-kB signaling/IFN response \\
\hline & \multirow{2}{*}{$\begin{array}{l}\text { VP16 } \\
\text { gC }\end{array}$} & UL48 & IRF3 & TLR3 /IFN response \\
\hline & & UL44 & $\mathrm{C} 3 \mathrm{~b}$ & complement activation \\
\hline & gE/gl & US8/US7 & $\operatorname{lgG}$ & neutralization/Ab dependent cytotoxicity \\
\hline & gM & UL10 & Tetherin & interferon-stimulated genes \\
\hline & gB & UL27 & PERK protein kinase & host translational arrest \\
\hline & ICP8 & UL29 & Stress granules & host translational arrest \\
\hline & \multirow{3}{*}{$\begin{array}{l}\text { Ser/Thr Protein } \\
\text { kinase }\end{array}$} & \multirow{3}{*}{ US3 } & IRF3 & TLRs signaling /IFN response \\
\hline & & & TRAF6 & TLRs signaling/IFN response \\
\hline & & & STING & DNA sensor signaling \\
\hline
\end{tabular}

For more details, see references 48 and 61. 


\begin{tabular}{|c|c|c|c|c|c|}
\hline \multirow{4}{*}{ 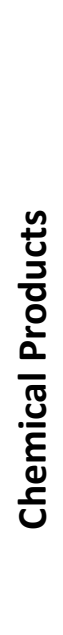 } & Class of Drugs & $\begin{array}{l}\text { Effect on } \\
\text { HSV-1 }\end{array}$ & Effect on AD & General effect & References \\
\hline & $\begin{array}{l}\text { Aciclic-guanosine } \\
\text { analogues: } \\
\text { Acyclovir, Ganciclovir, } \\
\text { Penciclovir, } \\
\text { Valaciclovir, } \\
\text { Famciclovir }\end{array}$ & $\begin{array}{l}\text { Reduction of } \\
\text { HSV-1 particles }\end{array}$ & $\begin{array}{l}\text { Reduction of } A \beta, \\
\text { decrease of } \\
\text { P-tau accumulation }\end{array}$ & $\begin{array}{l}\text { Reduction of disorders of } \\
\text { the micro-circulation } \\
\text { Bradycardia and treatmen } \\
\text { of pain } \\
\text { Bell's palsy (cranial nerve } \\
\text { lesion) }\end{array}$ & $\begin{array}{c} \\
{[140-143,} \\
166,167]\end{array}$ \\
\hline & $\begin{array}{l}\text { Pyrophosphate } \\
\text { analogues: } \\
\text { Foscarnet }\end{array}$ & $\begin{array}{l}\text { Reduction of } \\
\text { HSV-1 particles }\end{array}$ & $\begin{array}{l}\text { Reduction of } A \beta \text {, } \\
\text { decrease of } \\
\text { P-tau accumulation }\end{array}$ & $\begin{array}{l}\text { Alters antidiuretic } \\
\text { hormone mediated } \\
\text { transport water and urea }\end{array}$ & {$[140-143]$} \\
\hline & $\begin{array}{l}\text { Acyclic nucleotide } \\
\text { analogues: } \\
\text { Cidofovir, Adefovir }\end{array}$ & $\begin{array}{l}\text { Reduction of } \\
\text { HSV-1 particles }\end{array}$ & $\begin{array}{l}\text { Reduction of } A \beta \text {, } \\
\text { decrease of } \\
\text { P-tau accumulation }\end{array}$ & $\begin{array}{l}\text { Inhibits mitochondrial DNA } \\
\text { synthesis } \\
\text { Antiproliferative agents }\end{array}$ & $\begin{array}{l}{ }^{A}[140-143, \\
168,169]\end{array}$ \\
\hline \multirow{8}{*}{ 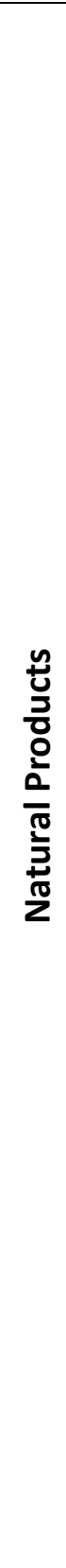 } & $\begin{array}{l}\text { Phytochemical: } \\
\text { Flavonoids, Alkaloids, } \\
\text { Terpenoids and } \\
\text { phenols }\end{array}$ & $\begin{array}{l}\text { Anti-viral } \\
\text { Anti- } \\
\text { inflammatory }\end{array}$ & $\begin{array}{l}\text { Protective role in } \\
\text { nervous system } \\
\text { disorders }\end{array}$ & $\begin{array}{l}\text { Anti-inflammatory } \\
\text { Anti cancer }\end{array}$ & [145] \\
\hline & $\begin{array}{l}\text { Flavonoids: } \\
\text { Flavanols, flavones, } \\
\text { Flavonols, isoflavones, } \\
\text { anthocyanidins }\end{array}$ & $\begin{array}{l}\text { Anti-viral } \\
\text { Anti-oxidant }\end{array}$ & $\begin{array}{l}\text { Cross BBB } \\
\text { Neuropharmacological } \\
\text { activities } \\
\text { Influencing protein } \\
\text { fusion and gene } \\
\text { expression }\end{array}$ & $\begin{array}{l}\text { Anti-oxidant } \\
\text { Anti cancer } \\
\text { Antiangiogenic }\end{array}$ & [145] \\
\hline & $\begin{array}{l}\text { Isoflavones: } \\
\text { Genistein, Daidzein }\end{array}$ & $\begin{array}{l}\text { Molecular } \\
\text { pathways } \\
\text { altered during } \\
\text { HSV-1 infection }\end{array}$ & $\begin{array}{l}\text { Neuroprotective } \\
\text { agent, antagonizing } \\
\text { the action of } \\
\text { estrogens }\end{array}$ & Osteogenic function & [146] \\
\hline & $\begin{array}{l}\text { Flavones: } \\
\text { Luteolin, Apigenin, } \\
\text { Acacetin }\end{array}$ & $\begin{array}{l}\text { Anti- } \\
\text { inflammatory } \\
\text { Anti-oxidative } \\
\text { Anti-viral }\end{array}$ & $\begin{array}{l}\text { Inhibit the activation } \\
\text { of proinflammatory } \\
\text { cytokines, } \\
\text { Protection AD } \\
\text { neurons }\end{array}$ & $\begin{array}{l}\text { Anti-inflammatory } \\
\text { Anti-oxidative }\end{array}$ & {$[147,148]$} \\
\hline & $\begin{array}{l}\text { Flavanols: } \\
\text { Epigallocatechin(EGCG) }\end{array}$ & $\begin{array}{l}\text { Molecular } \\
\text { pathways } \\
\text { altered during } \\
\text { HSV-1 infection }\end{array}$ & $\begin{array}{l}\text { Prevent neuronal cell } \\
\text { death }\end{array}$ & Cardiovascular function & {$[149,170]$} \\
\hline & $\begin{array}{l}\text { Anthocyanidin: } \\
\text { Cyanidin-3-glucoside } \\
\text { (C3G) }\end{array}$ & $\begin{array}{l}\text { Molecular } \\
\text { pathways } \\
\text { altered during } \\
\text { HSV-1 infection }\end{array}$ & $\begin{array}{l}\text { Neutralize the level of } \\
\text { A } \beta 1-42 \\
\text { peptides }\end{array}$ & Renal protective effect & {$[150,171]$} \\
\hline & $\begin{array}{l}\text { Flavonols: } \\
\text { Quercitin }\end{array}$ & $\begin{array}{l}\text { Sirt1 and AMPK } \\
\text { pathways } \\
\text { modulated by } \\
\text { HSV-1 } \\
\text { Anti-viral effects }\end{array}$ & $\begin{array}{l}\text { Neuroprotective } \\
\text { effects, block } \\
\text { accumulation of A } \beta \\
\text { peptides in vitro, } \\
\text { mediate the cleavage } \\
\text { of APP }\end{array}$ & $\begin{array}{l}\text { Anti-inflammatory } \\
\text { Anti-oxidative } \\
\text { Anti- apoptotic }\end{array}$ & $\begin{array}{l}{[152-156,} \\
158]\end{array}$ \\
\hline & $\begin{array}{l}\text { Endogenous fatty acid } \\
\text { amide (class of nuclear } \\
\text { factor agonists): } \\
\text { Palmitoylethanolamide } \\
\text { (PEA) }\end{array}$ & $\begin{array}{l}\text { Anti- } \\
\text { Inflammatory }\end{array}$ & $\begin{array}{l}\text { Neuroprotective } \\
\text { effects }\end{array}$ & Neurophatic pain & [159] \\
\hline
\end{tabular}

Table 3: Classes of drugs for the treatment of HSV-1 infection and Alzheimer Disease 
Figure 1

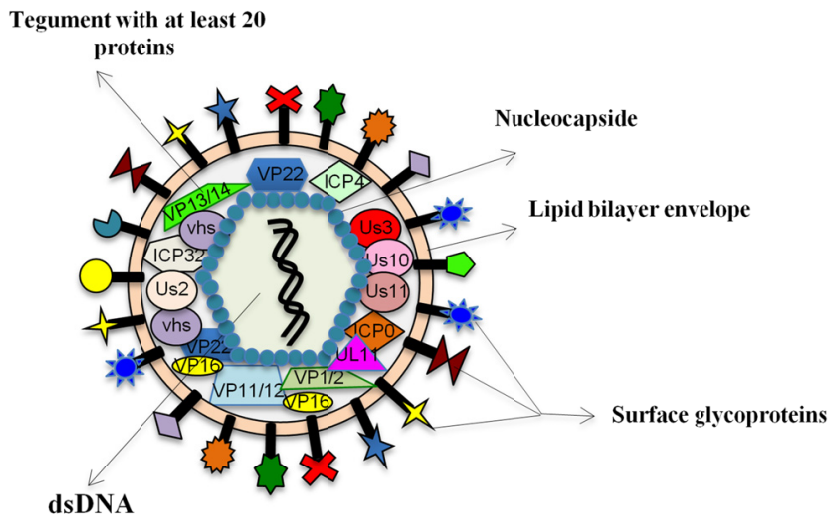


Figure 2

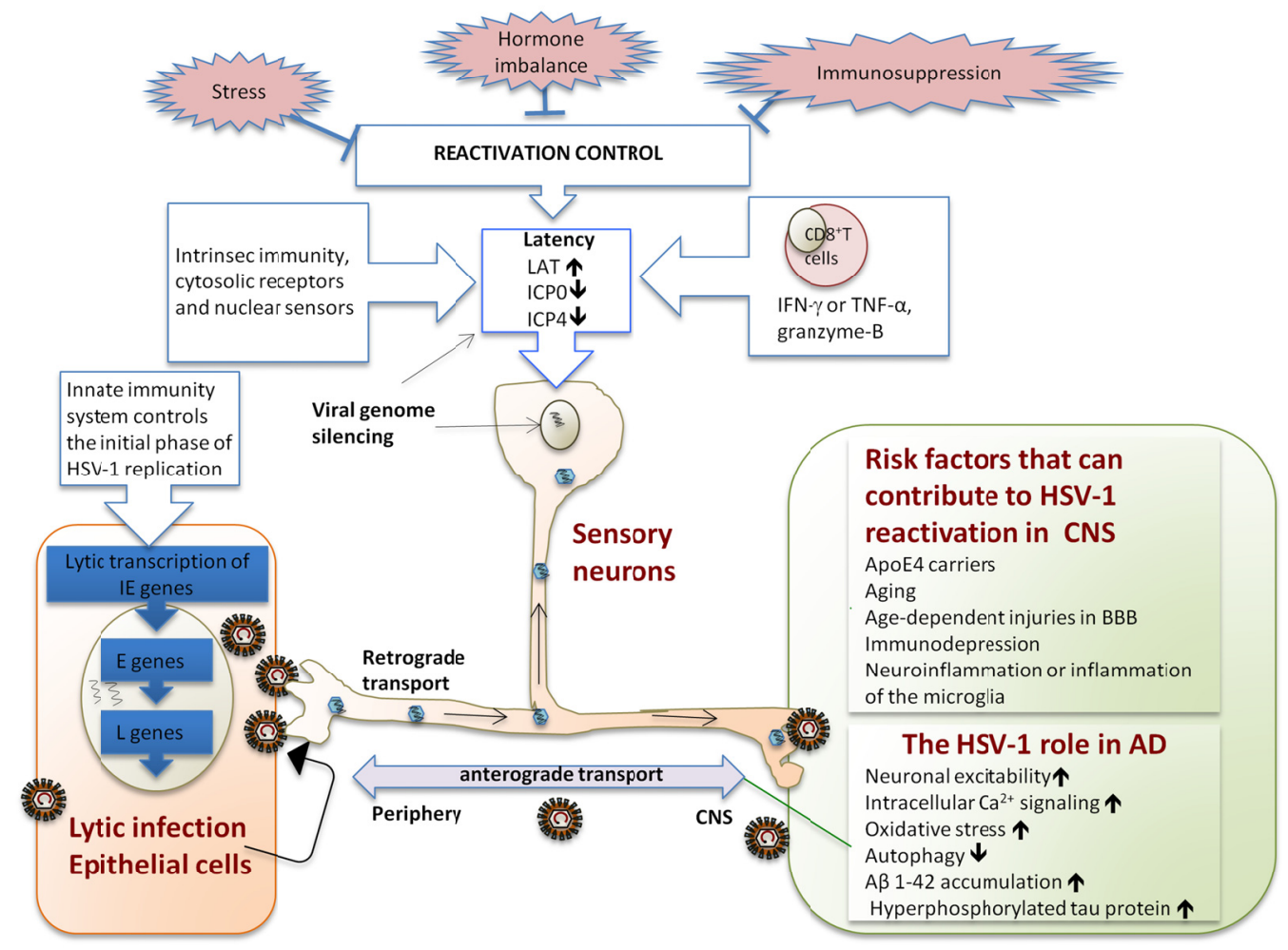

